\title{
EVOLUÇÃO DA COMPOSIÇÃO DAS CATEGORIAS OCUPACIONAIS DO \\ EMPREGO FORMAL, CONFORME OS SETORES DE ATIVIDADE, EM \\ 2003, 20082013
}

\author{
EVOLUTION OF THE COMPOSITION OF THE OCCUPATIONAL CATEGORIES OF \\ FORMAL EMPLOYMENT, ACCORDING TO THE SECTORS OF ACTIVITY, \\ 2003, 2008, 2013
}

Jacqueline Aslan Souen ${ }^{1}$

Classificação: JEL: E24

\section{RESUMO}

Entre 2003 e 2013 houve um intenso aumento do emprego formal, com expressiva elevação dos níveis das remunerações médias e diminuição da dispersão relativa destas, contribuindo para o aumento do nível de renda da população e redução da desigualdade, sendo este um aspecto fundamental do caráter socialmente inclusivo do crescimento da economia no período. Essa característica de maior inclusão social foi uma novidade no Brasil, onde aumentos na renda costumavam ser acompanhados de elevação da desigualdade. Contudo, não se verificou uma modificação mais substantiva da distribuição da estrutura ocupacional formal, o que exigiria transformações da distribuição do emprego formal por categoria ocupacional, as quais estão relacionadas não somente a alterações na composição das atividades da economia e na composição das ocupações, mas também a um processo de aperfeiçoamento no sistema de regulação do trabalho, o que forçaria deslocamentos de ocupações entre as categorias ocupacionais definidas conforme a renda média.

Palavras-chave: emprego formal; crescimento econômico; inclusão social; mercado de trabalho.

\begin{abstract}
There was an intense increase in formal employment between 2003 and 2013, with a significant increase in the levels of media remuneration and reduction of relative dispersion, contributing to the increase in the level of income of the population, with reduction of inequality, which is a fundamental aspect of the character socially inclusive growth of the economy in the period. This resource of greater social inclusion was a novelty in Brazil, where income items are usually accompanied by an increase in inequality. However, there was no more substantial change in the distribution of formal occupational structure, or what requires changes in the distribution of formal employment by occupational category, as these are related not only to changes in the composition of economic activities and in the composition of occupations, but also in the process of improving the work control system, or in the forced displacement of occupations between the occupied categories, according to the average income.
\end{abstract}

KEY WORDS: formal employment; economic growth; social inclusion; job market.

\footnotetext{
1 Doutora em Desenvolvimento Econômico, área de concentração: Economia Social e do Trabalho, pela Universidade Estadual de Campinas (UNICAMP). Professora do Instituto Latino-Americano de Economia, Sociedade e Política (ILAESP) da Universidade Federal de Integração Latini Americana (UNILA).
} 


\section{INTRODUÇÃO}

Entre 2003 e 2013 ocorreu expressivo aumento da quantidade de empregos formais, acompanhado de crescimento bem menor das outras posições na ocupação e da redução, em termos absolutos, das ocupações não remuneradas. Esse movimento possibilitou a elevação da quantidade de pessoas com emprego formal e contribuiu direta e indiretamente para o crescimento da renda do trabalho e para a diminuição da dispersão dos salários. Para isso, foi importante o menor crescimento do trabalho por conta própria, cuja dispersão das remunerações é maior do que a da renda do emprego formal, a qual ainda foi reduzida².

O intenso crescimento das ocupações formais possibilitou expressiva elevação dos salários nominais dessas ocupações, os quais, em termos reais, ainda foram beneficiados pela menor inflação do período. Os aumentos do valor do salário-mínimo e os reajustes dos salários das categorias profissionais acima da inflação foram os principais fatores responsáveis pela redução da dispersão desses salários em relação à média. Além desses fatores institucionais, a diminuição da dispersão também foi afetada por uma geração de empregos formais concentrada no nível intermediário das remunerações, entre a mediana e a média, comparativamente aos empregos de maior remuneração. Essa conformação na distribuição dos empregos formais não apenas reflete apenas o tipo de atividade que gerou esses empregos, mas também tem relação com a informalização de empregos de remuneração relativamente alta ${ }^{3}$.

$\mathrm{O}$ aumento da renda média do emprego formal, entretanto, foi menor do que o aumento da renda média do emprego sem carteira de trabalho. Isso se deve ao fato de que o salário-mínimo exerce um efeito maior sobre as remunerações mais próximas ao seu nível ${ }^{4}, \mathrm{o}$ que é o caso do emprego sem carteira. Além disso, a informalização dos empregos de maior renda também contribuiu para acentuar o aumento da renda média do emprego não formal e do trabalho por conta própria.

A despeito do aumento dos trabalhos por conta própria de maior remuneração, devido à informalização de empregos relativamente bem remunerados, o forte aumento do emprego formal, juntamente ao crescimento mais lento da PEA, além de absorver melhor as pessoas que entravam na atividade econômica, diminuiu a intensidade da expulsão de adultos sem qualificação. Isso reduziu a necessidade desses trabalhadores de buscar alternativas de sobrevivência por meio de negócio próprio de baixa renda, diminuindo a intensidade do crescimento do número de trabalhadores por conta própria, levando a aumentos dos níveis médios e à queda da dispersão das remunerações dessas ocupações.

Apesar de tais transformações no mercado de trabalho brasileiro, com significativa melhora na distribuição da renda do trabalho, não se verificou uma modificação mais substantiva da distribuição da estrutura ocupacional formal, o que exigiria transformações da distribuição do emprego formal por categoria ocupacional, as quais estão relacionadas não somente com alterações na composição das atividades da economia e das ocupações, mas também, e de suma importância, a um processo de aperfeiçoamento no sistema de regulação do trabalho, o que forçaria deslocamentos de ocupações entre as categorias ocupacionais definidas conforme a renda média.

2 Ver Medeiros (2015).

3 O aumento desproporcional dos empregos formais de remuneração intermediária reflete, de um lado, a formalização de atividades e contratos de trabalho de remunerações média e baixa e, de outro, a substituição de empregos formais por trabalho autônomo e de Pessoa Jurídica (PJ), em atividades de remuneração relativamente alta, visando esconder a relação de emprego e evitar os encargos trabalhistas.

4 Supondo que a maior proximidade do salário médio do emprego sem carteira em relação ao salário-mínimo é acompanhada de uma proporção relativamente elevada desses empregados com remuneração próxima do salário mínimo e que se verifica a hipótese de que o salário mínimo exerce um efeito tipo farol sobre esses empregados sem carteira de trabalho. Para mais detalhes, ver Saboia (2010). 
O objetivo do presente trabalho é analisar a evolução do emprego formal conforme as categorias ocupacionais por atividade econômica, observando as remunerações médias desses empregos, no período de crescimento econômico, entre 2003 e 2013, considerando o momento de aceleração do PIB, entre 2003 e 2008, e de desaceleração, entre 2008 e 2013, dado os efeitos da crise internacional.

Para essa análise foi utilizada uma classificação das categorias ocupacionais conforme a renda, levando-se em conta a variável remuneração média das ocupações formais, de acordo com os salários médios registrados em dezembro de 2013, conforme dados da RAIS. Essa classificação resultou em quatro grandes categorias de ocupação, conforme agrupação das ocupações descritas na Classificação Brasileira de Ocupações $^{5}$ (CBO 2002), no nível de dois dígitos, ou seja, o segundo nível de agregação dos subgrupos principais.

A primeira categoria de ocupação, chamada $\mathrm{A}$, de alta renda média, compõe-se das ocupações com rendas médias entre 2,0 e 4,9 vezes o salário médio geral. A categoria $\mathrm{B}$, de média-alta renda média, incorpora as ocupações com rendas médias entre 1,2 e 1,8 vez o salário médio geral. A categoria $\mathrm{C}$, de média-baixa renda média, agrega as ocupações com rendas médias entre 0,8 e 1,0 vez o salário médio geral. Para terminar, a categoria $\mathrm{D}$, de baixa renda média, contém as ocupações com rendas médias entre 0,5 a 0,7 vez o salário médio geral.

Conforme essa classificação, as categorias A e B, compostas pelos subgrupos principais de maiores salários médios, são formadas por ocupações de direção e profissionais de nível superior de educação, grande parte das ocupações técnicas de nível educacional médio e uma pequena parte de ocupações manuais da produção de bens e serviços industriais. Quanto às categorias $\mathrm{C}$ e $\mathrm{D}$, que englobam os subgrupos principais de menores salários médios, são formadas por uma minoria de ocupações técnicas de nível médio, a maioria das ocupações manuais da produção de bens e serviços industriais e todas as ocupações de serviços de apoio administrativo, de prestação de serviços, de vendas e de trabalho na agropecuária, na extração florestal e na pesca - ver Anexo 1.

Para realizar o cruzamento com os setores de atividade utilizou-se a Classificação Nacional de Atividades Econômicas (CNAE 95), agregada por meio do nível Seção, para os setores em geral, e pelo nível Divisão ${ }^{6}$, considerando os subsetores da indústria de transformação.

5 A Classificação Brasileira de Ocupações (CBO) é um documento elaborado pelo Ministério do Trabalho e Emprego (MTE), em conjunto com o Instituto Brasileiro de Geografia e Estatística (IBGE), que nomeia e codifica os títulos e descreve as características das ocupações do mercado de trabalho brasileiro. A primeira edição do documento foi elaborada em 1982 e, desde então, as alterações foram pontuais, sem modificações estruturais mais significativas. A versão de 1994 iniciou uma classificação unificada para o território nacional, o que facilitou, a partir daquela data, as comparações estatísticas dos diferentes órgãos nacionais, bem como a comparação com as informações internacionais. Essa versão foi substituída pela edição de 2002, quando ocorreu uma revisão e atualização completas, com modificações metodológicas, possibilitando maior integração das políticas públicas na área do mercado de trabalho. Para mais informações, ver: http://www.mtecbo.gov.br/ cbosite/pages/saibaMais.jsf.

6 A CNAE é composta por uma classificação estruturada hierarquicamente em cinco níveis, conforme a última atualização, CNAE 2.1, separados por 21 seções, 87 divisões, 285 grupos, 673 classes e 1.318 subclasses. Considerando a CNAE 95, ocorrem 18 conjuntos de atividades no nível Seção, incluindo as atividades não classificadas. No entanto, para efeito de análise, optou-se pela seguinte alteração: o setor "Agricultura, pecuária, silvicultura e exploração florestal" agrega o setor "Pesca"; o setor "Outros" é a agregação dos setores "Serviços domésticos" e "Organismos internacionais e outras instituições extraterritoriais"; o setor "Outros serviços coletivos, sociais e pessoais" está desagregado, conforme nível Divisão, em "Limpeza urbana e esgoto e atividades relacionadas", "Atividades associativas", "Atividades recreativas, culturais e desportivas" e "Serviços sociais e pessoais". Disponível em: http://subcomissaocnae.fazenda.pr.gov.br/modules/conteudo/conteudo. php?conteudo=4. Acesso em: 12 set. 2016. 
Além desta introdução e da conclusão, o presente artigo se divide em duas partes. $\mathrm{Na}$ primeira será analisada a composição da estrutura ocupacional do emprego formal conforme os setores de atividade em geral, levando em conta a fase de aceleração do PIB, entre 2003 e 2008, e a fase de desaceleração, entre 2008 e 2013. Na segunda parte, para o mesmo período, será feita uma abordagem considerando os subsetores da indústria de transformação.

\section{COMPOSIÇÃO DAS CATEGORIAS OCUPACIONAIS POR SETOR DE ATIVIDADE}

A composição do emprego formal por categorias de subgrupos principais varia entre os setores de atividade, e são grandes as diferenças de salários médios conforme os setores, considerando as mesmas categorias ocupacionais. Observando a evolução da composição ocupacional do emprego nos setores de atividade entre os anos de 2003, 2008 e 2013, percebese o predomínio da categoria D na maioria dos setores de atividade - Tabela 1.

Como mencionado, no Brasil a categoria D inclui grupos de ocupações que em países mais desenvolvidos e com um sistema de regulação de trabalho mais avançado e melhor distribuição de renda estariam na categoria $C$, que recebe salário médio mais próximo da média geral dos salários do emprego formal. Assim, em 2013, mais de 3/4 dos empregos formais foram gerados em subgrupos principais da categoria D nos setores "Alojamento e alimentação", "Limpeza urbana, esgoto e atividades relacionadas", "Agropecuária e pesca" e "Serviços sociais e pessoais". A participação da categoria D se mostrou também muito elevada, cerca de $2 / 3$, em setores como "Construção civil", "Comércio e reparação de veículos automotores, objetos pessoais e domésticos", "Transporte, armazenagem e comunicação" e "Atividades imobiliárias, aluguéis e serviços prestados às empresas". Mesmo em setores como "Indústria extrativa" e "Indústria de transformação", a participação da categoria D também se apresentou muito elevada, com taxas semelhantes a sua participação no total do emprego da RAIS, cerca de $50,0 \%$. A categoria D respondia ainda por grande parte dos empregos formais gerados em "Atividades associativas" e em "Atividades recreativas, culturais e desportivas" (40,0\%).

Esses doze setores de atividade, nos quais a maior parte dos empregos da RAIS foi gerada em subgrupos principais de menores salários médios, respondiam em conjunto por $70,0 \%$ do total de empregos da RAIS em 2013 - Tabela 2. Nos outros cinco setores, nos quais foram gerados os outros $30,0 \%$ de empregos da RAIS, foi muito menor a participação de ocupações da categoria D nos empregos gerados, variando de 8,4\%, em "Atividades financeiras", a 32,4\%, em "Saúde e serviços sociais" não públicos. Nesses dois setores e em "Produção e distribuição de eletricidade, gás e água", destacaram-se as ocupações da categoria $\mathrm{C}$ e, em "Educação" não pública, sobressaíram as ocupações da categoria $\mathrm{B}$, na qual foram gerados quase $50,0 \%$ dos empregos desse setor em 2013.

Assim, a maioria dos empregos formais que a atividade econômica gerou no Brasil nesse período ocorreu em subgrupos principais de salários médios menores do que a média geral dos empregos da RAIS. O tipo de ocupação dos empregos gerados é, então, importante para explicar as razões pelas quais $69,5 \%$ do total de empregos da RAIS em 2013 apresentava remunerações menores do que a média geral e somente $30,5 \%$ auferiam remunerações maiores do que a média, pois $76,5 \%$ dos empregos foram gerados em ocupações com salários médios menores que a média geral (categorias C e D) e somente $23,5 \%$ foram gerados em ocupações com salários médios maiores que a média geral (categorias A e B) - ver Tabela 3. Portanto, observando a composição do emprego formal no período, confirmou-se a predominância de empregos das categorias $\mathrm{C}$ e D como uma característica da maioria das atividades econômicas 
no Brasil. De fato, somente em "Indústria extrativa", "Produção e distribuição de eletricidade, água e gás", "Intermediação financeira, seguros, previdência complementar e serviços relacionados", "Administração pública, defesa e seguridade social", "Educação" não pública e "Atividades recreativas, culturais e desportivas", mais de 1/4 dos empregos formais gerados foi em subgrupos principais com salários médios maiores do que a média geral dos empregos da RAIS (categorias A e B).

\section{TABELA 1 - COMPOSIÇÃO DOS EMPREGOS DA RAIS CONFORME CATEGORIAS DE SUBGRUPOS PRINCIPAIS, NOS SETORES DE ATIVIDADE (\%)}

\begin{tabular}{|c|c|c|c|c|c|c|c|c|c|c|c|c|c|}
\hline \multirow{2}{*}{ Setores de Atividade } & \multicolumn{3}{|c|}{ Categoria A } & \multicolumn{3}{|c|}{ Categoria B } & \multicolumn{3}{|c|}{ Categoria $\mathbf{C}$} & \multicolumn{3}{|c|}{ Categoria D } & \multirow{2}{*}{ Total } \\
\hline & 2003 & 2008 & 2013 & 2003 & 2008 & 2013 & 2003 & 2008 & 2013 & 2003 & 2008 & 2013 & \\
\hline Agropecuária e pesca & 2,0 & 2,2 & 2,9 & 1,2 & 1,2 & 1,5 & 10,0 & 11,7 & 15,5 & 86,8 & 84,9 & 80,1 & 100 \\
\hline Indústrias extrativas & 6,6 & 13,6 & 12,7 & 16,8 & 19,8 & 20,6 & 20,9 & 19,5 & 21,5 & 55,7 & 47,1 & 45,3 & 100 \\
\hline $\begin{array}{l}\text { Indústrias de } \\
\text { transformação }\end{array}$ & 4,7 & 4,8 & 5,7 & 11,6 & 11,3 & 12,3 & 29,4 & 30,8 & 31,8 & 54,3 & 53,2 & 50,2 & 100 \\
\hline $\begin{array}{l}\text { Prod. e distrib. de } \\
\text { eletr., gás e agua }\end{array}$ & 16,4 & 18,8 & 16,8 & 21,3 & 17,2 & 19,7 & 47,6 & 50,3 & 49,7 & 14,6 & 13,7 & 13,8 & 100 \\
\hline Construção & 3,5 & 3,4 & 3,6 & 6,0 & 6,1 & 6,9 & 20,1 & 19,0 & 19,8 & 70,3 & 71,5 & 69,6 & 100 \\
\hline Comercio e reparação & 8,2 & 8,2 & 8,4 & 5,7 & 5,4 & 5,1 & 20,6 & 21,1 & 21,0 & 65,6 & 65,3 & 65,4 & 100 \\
\hline $\begin{array}{l}\text { Alojamento e } \\
\text { alimentação }\end{array}$ & 6,1 & 6,0 & 6,9 & 1,6 & 1,2 & 1,2 & 6,8 & 6,4 & 6,8 & 85,5 & 86,4 & 85,2 & 100 \\
\hline $\begin{array}{l}\text { Transp., armaz. e } \\
\text { comunicações }\end{array}$ & 5,2 & 5,4 & 6,1 & 7,7 & 7,9 & 8,7 & 21,0 & 21,3 & 21,4 & 66,1 & 65,4 & 63,8 & 100 \\
\hline $\begin{array}{l}\text { Inter. financeira, } \\
\text { seguros, previd. }\end{array}$ & 31,5 & 26,0 & 29,8 & 10,1 & 10,3 & 8,0 & 51,3 & 55,2 & 53,8 & 7,1 & 8,4 & 8,4 & 100 \\
\hline $\begin{array}{l}\text { Ativid. imob., alug. e } \\
\text { serv às empresas }\end{array}$ & 6,5 & 7,7 & 9,8 & 8,4 & 8,5 & 8,7 & 22,0 & 20,2 & 19,6 & 63,2 & 63,6 & 62,0 & 100 \\
\hline $\begin{array}{l}\text { Adm. Pub., defesa e } \\
\text { seguridade social }\end{array}$ & 13,6 & 14,6 & 16,7 & 30,0 & 28,4 & 29,2 & 35,9 & 36,0 & 33,4 & 20,4 & 20,9 & 20,7 & 100 \\
\hline Educação & 5,6 & 6,3 & 7,4 & 50,3 & 49,1 & 47,6 & 27,9 & 29,5 & 30,9 & 16,1 & 15,1 & 14,1 & 100 \\
\hline $\begin{array}{l}\text { Saúde e serviços } \\
\text { sociais }\end{array}$ & 13,9 & 16,3 & 18,1 & 5,9 & 4,6 & 3,7 & 42,5 & 43,8 & 45,8 & 37,6 & 35,3 & 32,4 & 100 \\
\hline $\begin{array}{l}\text { Limp. urbana, esgoto } \\
\text { e ativid. relacion. }\end{array}$ & 3,2 & 2,8 & 3,1 & 2,8 & 2,5 & 3,7 & 10,4 & 10,0 & 11,2 & 83,6 & 84,7 & 82,0 & 100 \\
\hline $\begin{array}{l}\text { Atividades } \\
\text { associativas }\end{array}$ & 9,5 & 10,6 & 12,5 & 15,9 & 13,3 & 12,8 & 30,7 & 34,4 & 34,6 & 43,9 & 41,8 & 40,1 & 100 \\
\hline $\begin{array}{l}\text { Ativid. recreat., } \\
\text { cultural. e desportiva }\end{array}$ & 10,4 & 12,0 & 15,1 & 16,3 & 16,0 & 16,8 & 27,6 & 29,4 & 27,9 & 45,6 & 42,7 & 40,2 & 100 \\
\hline $\begin{array}{l}\text { Serviços sociais e } \\
\text { pessoais }\end{array}$ & 5,5 & 4,3 & 5,1 & 4,6 & 3,3 & 2,5 & 14,5 & 13,1 & 15,4 & 75,4 & 79,2 & 77,0 & 100 \\
\hline Outros & 5,0 & 4,5 & 13,8 & 3,4 & 4,3 & 4,0 & 7,1 & 12,2 & 23,8 & 84,5 & 79,1 & 58,5 & 100 \\
\hline$\{\tilde{n}$ class $\}$ & 2,3 & 1,4 & 0,0 & 5,8 & 0,0 & 0,0 & 18,4 & 17,4 & 0,0 & 73,5 & 81,2 & 0,0 & 100 \\
\hline Total & 8,7 & 8,9 & 10,0 & 14,7 & 13,6 & 13,5 & 27,2 & 27,3 & 26,7 & 49,5 & 50,2 & 49,8 & 100 \\
\hline
\end{tabular}

Fonte: RAIS. Elaboração própria. 
É possível então afirmar que o crescimento com inclusão social não modificou substancialmente a composição dos empregos formais por categorias de subgrupos principais dos setores de atividade. A participação dos empregos das duas categorias de subgrupos principais de salários médios maiores do que a média geral dos salários dos empregos da RAIS (categorias A e B) aumentou, significativamente, somente em "Indústria extrativa" e em "Atividades recreativas, culturais e desportivas". Porém, o fato de as ocupações das categorias C e D predominarem nos empregos formais gerados no crescimento com inclusão social reflete menos a natureza das atividades, que se expandiram naquele crescimento, e mais a permanência nas categorias $\mathrm{C}$ e $\mathrm{D}$ de ocupações que, caso tivéssemos um sistema mais avançado de regulação do trabalho e uma melhor distribuição de renda, estariam em categorias de maiores salários médios, ou seja, algumas ocupações que em 2013 se encontravam na categoria D poderiam estar na categoria $\mathrm{C}$, e algumas ocupações que estavam em $\mathrm{C}$ poderiam estar na categoria $\mathrm{B}$.

\section{TABELA 2 - EVOLUÇÃO DO EMPREGO FORMAL POR SETOR DE ATIVIDADE, 2003, 2008, 2013}

\begin{tabular}{|c|c|c|c|c|c|c|c|c|}
\hline \multirow{2}{*}{ Setores de Atividade } & \multirow{2}{*}{$\mathbf{N}^{0}$ Abs 2003} & \multirow{2}{*}{$\begin{array}{c}\text { Part. } \\
2003 \\
(\%)\end{array}$} & \multirow{2}{*}{$\begin{array}{c}\mathbf{N}^{\circ} \text { Abs. } \\
2008\end{array}$} & \multirow{2}{*}{$\begin{array}{c}\text { Part. } \\
2008 \\
(\%)\end{array}$} & \multirow{2}{*}{$\begin{array}{c}\text { No Abs. }^{\circ} \\
2013\end{array}$} & \multirow{2}{*}{$\begin{array}{c}\text { Part. } \\
2013 \\
(\%)\end{array}$} & \multicolumn{2}{|c|}{$\operatorname{Var}(\%)$} \\
\hline & & & & & & & $2003 / 08$ & $2008 / 13$ \\
\hline Agropecuária e pesca & 1.436 .198 & 4,8 & 1.726 .345 & 4,2 & 1.668 .706 & 3,3 & 20,2 & $-3,3$ \\
\hline Indústrias extrativas & 122.899 & 0,4 & 209.191 & 0,5 & 265.059 & 0,5 & 70,2 & 26,7 \\
\hline $\begin{array}{l}\text { Indústrias de transfor- } \\
\text { mação }\end{array}$ & 5.357 .643 & 17,9 & 7.499 .491 & 18,4 & 8.217 .451 & 16,5 & 40,0 & 9,6 \\
\hline $\begin{array}{l}\text { Prod. e distrib. de } \\
\text { eletr., gás e água }\end{array}$ & 208.186 & 0,7 & 240.215 & 0,6 & 259.804 & 0,5 & 15,4 & 8,2 \\
\hline Construção & 1.091 .386 & 3,6 & 2.026 .433 & 5,0 & 3.017 .100 & 6,0 & 85,7 & 48,9 \\
\hline Comercio e reparação & 5.015 .960 & 16,7 & 7.189 .557 & 17,7 & 9.318 .517 & 18,7 & 43,3 & 29,6 \\
\hline $\begin{array}{l}\text { Alojamento e alimen- } \\
\text { tação }\end{array}$ & 879.062 & 2,9 & 1.302 .811 & 3,2 & 1.804 .067 & 3,6 & 48,2 & 38,5 \\
\hline $\begin{array}{l}\text { Transp., armaz. e } \\
\text { comunicações }\end{array}$ & 1.472 .127 & 4,9 & 2.006 .535 & 4,9 & 2.734 .583 & 5,5 & 36,3 & 36,3 \\
\hline $\begin{array}{l}\text { Interm. financeira, } \\
\text { seguros, previd. }\end{array}$ & 573.541 & 1,9 & 736.316 & 1,8 & 851.158 & 1,7 & 28,4 & 15,6 \\
\hline $\begin{array}{l}\text { Ativid. imob., alug. e } \\
\text { serv às empresas }\end{array}$ & 3.197 .503 & 10,7 & 4.468 .996 & 11,0 & 6.166 .280 & 12,4 & 39,8 & 38,0 \\
\hline $\begin{array}{l}\text { Adm. Pub., defesa e } \\
\text { segurid. social }\end{array}$ & 7.189 .000 & 24,0 & 8.922 .076 & 21,9 & 10.014 .103 & 20,1 & 24,1 & 12,2 \\
\hline Educação & 964.645 & 3,2 & 1.401 .209 & 3,4 & 1.848 .648 & 3,7 & 45,3 & 31,9 \\
\hline $\begin{array}{l}\text { Saúde e serviços } \\
\text { sociais }\end{array}$ & 1.166 .930 & 3,9 & 1.462 .382 & 3,6 & 2.002 .226 & 4,0 & 25,3 & 36,9 \\
\hline $\begin{array}{l}\text { Limp. urbana, esgoto e } \\
\text { ativid. relacion. }\end{array}$ & 109.921 & 0,4 & 140.037 & 0,3 & 186.294 & 0,4 & 27,4 & 33,0 \\
\hline Atividades associativas & 762.471 & 2,5 & 881.600 & 2,2 & 875.261 & 1,8 & 15,6 & $-0,7$ \\
\hline $\begin{array}{l}\text { Ativid. Recreat., cultur. } \\
\text { e desport. }\end{array}$ & 272.122 & 0,9 & 309.930 & 0,8 & 409.121 & 0,8 & 13,9 & 32,0 \\
\hline
\end{tabular}




\begin{tabular}{lcccccccc}
\hline $\begin{array}{l}\text { Serviços sociais e } \\
\text { pessoais }\end{array}$ & 134.706 & 0,4 & 172.176 & 0,4 & 221.544 & 0,4 & 27,8 & 28,7 \\
\hline Outros & 10.719 & 0,0 & 17.674 & 0,0 & 10.849 & 0,0 & 64,9 & $-38,6$ \\
\hline$\{\tilde{n}$ class $\}$ & 933 & 0,0 & 69 & 0,0 & - & - & $-92,6$ & - \\
\hline Total & 29.965 .952 & 100 & 40.713 .043 & 100 & 49.870 .771 & 100 & 35,9 & 22,5 \\
\hline
\end{tabular}

Fonte: RAIS. Elaboração própria.

Nota: Cálculo baseado nos estoques dos meses de setembro. Para setores de atividade utilizado CNAE 95 seção.

Além da composição ocupacional de empregos ser diferente entre os setores de atividade, são também grandes as diferenças setoriais de salários médios para a mesma categoria ocupacional - ver Tabela 4. Assim, por exemplo, o salário médio da categoria A em 2013 equivalia a oito salários mínimos, mas a média salarial da categoria A variou de 20,8 salários mínimos na "Indústria extrativa" para 2,8 salários mínimos nos "Serviços pessoais". Relativamente ao salário médio da categoria, o desvio-padrão dos salários médios setoriais foi mais alto nas categorias A e C e mais baixo nas categorias B e D - Tabela 5.

TABELA 3 - DISTRIBUIÇÃO DOS EMPREGOS DA RAIS POR CATEGORIAS DE SUBGRUPOS PRINCIPAIS, 2003, 2008 e 2013 (\%)

\begin{tabular}{cccccc}
\hline \multirow{2}{*}{ Categorias } & \multicolumn{3}{c}{ Participação } & \multicolumn{3}{c}{ Variação } \\
\cline { 2 - 6 } & $\mathbf{2 0 0 3}$ & $\mathbf{2 0 0 8}$ & $\mathbf{2 0 1 3}$ & $\mathbf{2 0 0 3 - 2 0 0 8}$ & $\mathbf{2 0 0 8 - 2 0 1 3}$ \\
\hline A & 8,7 & 8,9 & 10,0 & 39,7 & 37,8 \\
\hline B & 14,7 & 13,6 & 13,5 & 26,3 & 21,6 \\
\hline C & 27,2 & 27,3 & 26,7 & 36,2 & 19,8 \\
\hline D & 49,5 & 50,2 & 49,8 & 37,9 & 21,5 \\
\hline Total & 100 & 100 & 100 & 35,9 & 22,5 \\
\hline
\end{tabular}

Fonte: RAIS. Elaboração própria.

\section{TABELA 4 - SALÁRIOS MÉDIOS DAS CATEGORIAS DE SUBGRUPOS PRINCIPAIS POR SETORES DE ATIVIDADE, EM NÚMEROS DE SALÁRIOS MÍNIMOS, DEZ 2013}

\begin{tabular}{|c|c|c|c|c|c|}
\hline \multirow{2}{*}{ Setores de atividade } & \multicolumn{4}{|c|}{ Categorias } & \multirow{2}{*}{ Total } \\
\hline & $\mathbf{A}$ & B & $\mathbf{C}$ & D & \\
\hline Agropecuária e pesca & 5,9 & 3,6 & 2,7 & 1,6 & 1,9 \\
\hline Indústrias extrativas & 20,8 & 11,8 & 4,8 & 3,7 & 7,8 \\
\hline Indústrias de transformação & 11,3 & 4,9 & 3,1 & 2,0 & 3,3 \\
\hline Prod. e distrib. de eletr., gas e agua & 15,5 & 8,8 & 5,5 & 3,6 & 7,6 \\
\hline
\end{tabular}




\begin{tabular}{llllll}
\hline Construção & 9,7 & 4,3 & 2,8 & 2,1 & 2,7 \\
\hline Comercio e reparação & 5,1 & 3,1 & 2,0 & 1,8 & 2,2 \\
\hline Alojamento e alimentação & 3,1 & 2,4 & 1,8 & 1,5 & 1,6 \\
\hline Transp., armaz. e comunicações & 9,8 & 4,4 & 2,9 & 2,3 & 3,1 \\
\hline Interm. financeira, seguros, previd. & 11,0 & 5,0 & 6,6 & 2,6 & 7,4 \\
\hline Ativid. imob., alug. e serv às empresas & 8,5 & 3,8 & 2,4 & 1,8 & 2,7 \\
\hline Adm. Pub., defesa e seguridade social & 8,1 & 5,0 & 3,7 & 2,4 & 4,6 \\
\hline Educação & 8,0 & 5,7 & 2,8 & 1,9 & 4,4 \\
\hline Saúde e serviços sociais & 6,8 & 3,2 & 2,4 & 1,6 & 3,0 \\
\hline Limp. urbana, esgoto e ativid. relacion. & 8,4 & 4,2 & 2,9 & 1,9 & 2,3 \\
\hline Atividades associativas & 6,2 & 3,4 & 2,2 & 1,6 & 2,6 \\
\hline Ativid. recreat., cultur. e desport. & 4,9 & 4,5 & 3,1 & 1,6 & 3,0 \\
\hline Serviços sociais e pessoais & 2,8 & 2,1 & 1,7 & 1,4 & 1,6 \\
\hline Outros & 6,6 & 4,3 & 3,0 & 1,7 & 2,8 \\
\hline Total & 8,0 & 4,8 & 3,1 & 1,9 & 3,2 \\
\hline
\end{tabular}

Fonte: RAIS. Elaboração própria.

No crescimento com inclusão social, houve diminuição do coeficiente de variação dos salários médios setoriais nas categorias $\mathrm{A}$ e $\mathrm{B}$, enquanto na categoria $\mathrm{C}$ praticamente não houve alteração e, na categoria $\mathrm{D}$, o coeficiente de variação modificou-se muito pouco. Destacase a magnitude elevada do desvio-padrão dos salários médios setoriais da Categoria $\mathrm{C}$ que, relativamente ao salário médio da categoria, é maior do que na categoria $\mathrm{B}$, e que a diferença aumentou no crescimento com inclusão social - Tabela 5.

Como sugerido anteriormente, o contraste entre a estrutura salarial do Brasil e a de países com um sistema de regulação do trabalho mais avançado e melhor distribuição de renda indica que o movimento de melhora na regulação do trabalho e na distribuição de renda possibilitaria o deslocamento para cima de algumas ocupações entre as categorias D, C e B. Deslocamentos desse tipo tenderiam a diminuir o coeficiente de variação dos salários médios setoriais da categoria $\mathrm{C}$. Atualmente, algumas ocupações da categoria $\mathrm{C}$ já têm remunerações relativamente elevadas em alguns setores de atividade, com destaque para algumas ocupações manuais do setor manufatureiro. A imposição de pisos salariais mais elevados nessas ocupações, por meio de um sistema de regulação mais efetivo, elevaria a média salarial e diminuiria a dispersão dos salários entre os setores de atividade, promovendo o deslocamento dessas ocupações da categoria $\mathrm{C}$ para a $\mathrm{B}$. 


\section{TABELA 5 - COEFICIENTE DE VARIAÇÃO DOS SALÁRIOS MÉDIOS SETORIAIS POR CATEGORIAS DE SUBGRUPOS PRINCIPAIS, 2003, 2008, 2013}

\begin{tabular}{cccc}
\hline Categorias & $\mathbf{2 0 0 3}$ & $\mathbf{2 0 0 8}$ & $\mathbf{2 0 1 3}$ \\
\hline A & 0,372 & 0,358 & 0,295 \\
\hline B & 0,283 & 0,249 & 0,214 \\
\hline C & 0,311 & 0,307 & 0,308 \\
\hline D & 0,162 & 0,163 & 0,154 \\
\hline
\end{tabular}

Fonte: RAIS. Elaboração própria.

Uma dessas categorias ocupacionais manuais da categoria $\mathrm{C}$, presente em setores estratégicos do nosso desenvolvimento, e que explicita a fragilidade do nosso sistema de regulação do trabalho, caracterizado por processos de negociações coletivas bastante descentralizados, são os trabalhadores metalúrgicos.

Como exemplificado no Anexo 1 os pisos salariais da categoria, de acordo com alguns estados selecionados, variam conforme a localidade, o tamanho da empresa, o ramo da indústria etc., chegando a uma diferença de mais de 76,0\% em 2013 entre o piso mais baixo, nas empresas de até 30 trabalhadores, no estado do Rio de Janeiro, e o piso mais elevado, nas empresas de mais de 150 trabalhadores, no estado de São Paulo. Considerando somente este último estado, a diferença entre os pisos chega a quase $40,0 \%$ entre, por um lado, as empresas de até 100 trabalhadores dos segmentos de lâmpadas, equipamentos odontológicos, iluminação, material bélico e outros e, por outro lado, as empresas de mais de 150 trabalhadores do segmento de autopeças, com os maiores pisos. Reforçando ainda que a abrangência territorial e setorial dos pisos salariais descritos para cada estado varia conforme a força de organização e atuação dos sindicatos da categoria em cada localidade. Essa é uma ocupação que está presente em muitos setores e tem número elevado de empregos distribuídos em diferentes tipos de empresas, de variados tamanhos e em distintas regiões do país, com uma organização sindical bastante descentralizada e com distinta força de atuação, o que dificulta a imposição de um piso unificado e mais elevado?.

Portanto, o processo de regulação existente não é capaz de estabelecer um piso salarial mais próximo dos salários dos setores e empresas que têm mais condições de pagar melhores remunerações. Dessa forma, para essa categoria ocupacional, assim como para tantas outras, ocorre uma dispersão salarial bastante elevada, contribuindo para reduzir da média salarial, o

\footnotetext{
Para ilustrar tal dificuldade, um estudo feito em 2011 para o estado do Paraná pela Federação dos Metalúrgicos do Paraná (Fetim), utilizando dados do Dieese, constatou que, na cidade de Ponta Grossa, o piso salarial dos trabalhadores da reparação de veículos, considerando o ano de 2011 (com data-base em setembro), variava entre R\$ 600,00 e R \$ 700,00, valores bastante inferiores se comparados aos pisos pagos em Curitiba, entre $\mathrm{R} \$ 950,00$ e R\$ 1.050,00, para a mesma ocupação e ramo de atividade. A diferença ficou ainda maior quando comparados os pisos de Ponta Grossa com os pisos salariais das montadoras Renault e Volkswagen do município de São José dos Pinhais, cujo valor era de R\$ 1.700,00. Entre Londrina e Maringá, os pisos com data-base em dezembro também registraram diferenças, $\mathrm{R} \$ 910,80$ e $\mathrm{R} \$ 890,00$, respectivamente, ainda muito aquém do piso de Curitiba, com a mesma data-base, $\mathrm{R} \$ 1.049,40$. O estudo destacou também a discrepância dos pisos realizados para a mesma indústria, no caso da Hubner, com fábrica em Ponta Grossa, onde o piso salarial era de R \$ 800,00, e Curitiba, onde a mesma indústria pagava um piso de R\$ 1.150,00 (Disponível em: http://www. simec.com.br/?area=ver_noticia\&id=1914. Acesso em: 2 set. 2017).
} 
que faz com que a ocupação seja classificada, conforme sua renda, na categoria $\mathrm{C}$, em vez de na categoria $\mathrm{B}$.

$\mathrm{Na}$ categoria $\mathrm{C}$, os salários médios em 2013 se mostraram elevados nos setores de "Finanças", "Produção e distribuição de eletricidade, água e gás" e "Indústria extrativa", nos quais é elevada a concentração da atividade nas grandes empresas - ver Tabela 4. A maior parte dos empregos da categoria $\mathrm{C}$, entretanto, foi gerada nos setores "Administração pública" (25,1\%), "Indústria de transformação" (19,7\%), "Comércio e reparação" (14,7\%), "Atividades imobiliárias e serviços para empresas" (9,1\%), "Saúde e serviços sociais" (6,9\%). Outros setores, com participação não desprezível nos empregos das ocupações da categoria $\mathrm{C}$, foram "Produção e distribuição de eletricidade, água e gás" (4,5\%), "Transporte, armazenagem e comunicação" (4,4\%), "Educação" (4,3\%) e "Serviços financeiros" (3,4\%) - Tabela 6.

Na categoria D, os salários médios em 2013 também foram relativamente elevados nos setores de "Indústria extrativa", "Produção e distribuição de eletricidade, água e gás" e "Serviços financeiros", nos dois primeiros setores, superando a média geral da categoria imediatamente superior - ver Tabela 4. A maior parte do emprego da categoria $\mathrm{D}$, entretanto, foi gerada em "Comércio e reparação" (24,6\%), "Indústria de transformação" (16,6\%), "Atividades imobiliárias, aluguéis e serviços prestados a empresas" (15,4\%), "Construção civil" (8,5\%), "Administração pública" $(8,4 \%)$, "Transporte, armazenagem e comunicação" (7\%), "Alojamento e alimentação" (6,2\%) e "Agropecuária e pesca" (5,4\%) - Tabela 6.

Confirmando o peso atual da grande empresa na determinação dos níveis dos salários e a debilidade ainda existente na regulação pública do trabalho, na categoria A também se destacaram os salários médios de setores como "Indústria extrativa", "Produção e distribuição de eletricidade, água e gás" e "Serviços financeiros", mas o emprego em ocupações dessa categoria foi gerado principalmente em "Administração pública" (33,5\%), "Comércio e reparação" (15,7\%), "Atividades imobiliárias, aluguéis e serviços prestados a empresas" (12\%), "Indústria de transformação" (9,3\%), "Saúde e serviços sociais" (7,3\%), "Serviços financeiros" $(5,1 \%)$ e "Transporte, armazenagem e comunicações" (3,4\%) - Tabela 6.

TABELA 6 - COMPOSIÇÃO DO EMPREGO FORMAL CONFORME SETORES DE ATIVIDADE, NAS CATEGORIAS DE SUBGRUPOS PRINCIPAIS (\%)

\begin{tabular}{lccccccccccccc}
\hline \multirow{2}{*}{ Setores de Atividade } & \multicolumn{3}{c}{ Categoria A } & \multicolumn{3}{c}{ Categoria B } & \multicolumn{3}{c}{ Categoria C } & \multicolumn{3}{c}{ Categoria D } \\
\cline { 2 - 12 } & $\mathbf{2 0 0 3}$ & $\mathbf{2 0 0 8}$ & $\mathbf{2 0 1 3}$ & $\mathbf{2 0 0 3}$ & $\mathbf{2 0 0 8}$ & $\mathbf{2 0 1 3}$ & $\mathbf{2 0 0 3}$ & $\mathbf{2 0 0 8}$ & $\mathbf{2 0 1 3}$ & $\mathbf{2 0 0 3}$ & $\mathbf{2 0 0 8}$ & $\mathbf{2 0 1 3}$ \\
\hline Agropecuária e pesca & 1,1 & 1,1 & 1,0 & 0,4 & 0,4 & 0,4 & 1,8 & 1,8 & 1,9 & 8,4 & 7,2 & 5,4 \\
Indústrias extrativas & 0,3 & 0,8 & 0,7 & 0,5 & 0,7 & 0,8 & 0,3 & 0,4 & 0,4 & 0,5 & 0,5 & 0,5 \\
$\begin{array}{l}\text { Indústrias de transfor- } \\
\text { mação }\end{array}$ & 9,8 & 9,9 & 9,3 & 14,2 & 15,2 & 15,0 & 19,3 & 20,8 & 19,7 & 19,6 & 19,5 & 16,6 \\
$\begin{array}{l}\text { Prod. e distrib. de eletr., } \\
\text { gas e agua }\end{array}$ & 1,3 & 1,2 & 0,9 & 1,0 & 0,7 & 0,8 & 1,2 & 1,1 & 1,0 & 0,2 & 0,2 & 0,1 \\
$\begin{array}{l}\text { Construção } \\
\text { Comercio e reparação }\end{array}$ & 1,5 & 1,9 & 2,2 & 1,5 & 2,2 & 3,1 & 2,7 & 3,5 & 4,5 & 5,2 & 7,1 & 8,5 \\
$\begin{array}{l}\text { Alojamento e alimen- } \\
\text { tação }\end{array}$ & 2,1 & 2,1 & 2,5 & 0,3 & 0,3 & 0,3 & 0,7 & 0,8 & 0,9 & 5,1 & 5,5 & 6,2
\end{tabular}




\begin{tabular}{lccccccccccccc}
$\begin{array}{l}\text { Transp., armaz. e co- } \\
\text { municações }\end{array}$ & 2,9 & 3,0 & 3,4 & 2,6 & 2,8 & 3,5 & 3,8 & 3,9 & 4,4 & 6,6 & 6,4 & 7,0 \\
$\begin{array}{l}\text { Interm. financeira, } \\
\text { seguros, previd. }\end{array}$ & 7,0 & 5,3 & 5,1 & 1,3 & 1,4 & 1,0 & 3,6 & 3,7 & 3,4 & 0,3 & 0,3 & 0,3 \\
$\begin{array}{l}\text { Ativid. imob., alug. e } \\
\text { serv às empresas }\end{array}$ & 7,9 & 9,5 & 12,0 & 6,1 & 6,8 & 7,9 & 8,6 & 8,1 & 9,1 & 13,6 & 13,9 & 15,4 \\
$\begin{array}{l}\text { Adm. Pub., defesa e } \\
\text { seguridade social }\end{array}$ & 37,7 & 36,0 & 33,5 & 49,0 & 45,7 & 43,2 & 31,7 & 29,0 & 25,1 & 9,9 & 9,1 & 8,4 \\
Educação & 2,1 & 2,4 & 2,7 & 11,0 & 12,4 & 13,0 & 3,3 & 3,7 & 4,3 & 1,0 & 1,0 & 1,0 \\
Saúde e serviços sociais & 6,3 & 6,6 & 7,3 & 1,6 & 1,2 & 1,1 & 6,1 & 5,8 & 6,9 & 3,0 & 2,5 & 2,6 \\
$\begin{array}{l}\text { Limp. urbana, esgoto e } \\
\text { ativid. relacion. }\end{array}$ & 0,1 & 0,1 & 0,1 & 0,1 & 0,1 & 0,1 & 0,1 & 0,1 & 0,2 & 0,6 & 0,6 & 0,6 \\
Atividades associativas & 2,8 & 2,6 & 2,2 & 2,8 & 2,1 & 1,7 & 2,9 & 2,7 & 2,3 & 2,3 & 1,8 & 1,4 \\
$\begin{array}{l}\text { Ativid. Recreat., cultur. } \\
\text { e desport. }\end{array}$ & 1,1 & 1,0 & 1,2 & 1,0 & 0,9 & 1,0 & 0,9 & 0,8 & 0,9 & 0,8 & 0,6 & 0,7 \\
$\begin{array}{l}\text { Serviços sociais e } \\
\text { pessoais }\end{array}$ & 0,3 & 0,2 & 0,2 & 0,1 & 0,1 & 0,1 & 0,2 & 0,2 & 0,3 & 0,7 & 0,7 & 0,7 \\
Outros & 0,0 & 0,0 & 0,0 & 0,0 & 0,0 & 0,0 & 0,0 & 0,0 & 0,0 & 0,1 & 0,1 & 0,0 \\
\{ñ class & 0,0 & 0,0 & 0,0 & 0,0 & 0,0 & 0,0 & 0,0 & 0,0 & 0,0 & 0,0 & 0,0 & 0,0 \\
\hline Total & 100 & 100 & 100 & 100 & 100 & 100 & 100 & 100 & 100 & 100 & 100 & 100 \\
\hline
\end{tabular}

Fonte: RAIS. Elaboração própria.

A desaceleração do crescimento do emprego formal da indústria de transformação, após a crise internacional de 2008, que resultou em uma redução de quase $1 / 3$ da contribuição desse setor para o crescimento do conjunto do emprego formal, impactou fortemente na desaceleração geral do crescimento do emprego formal. O comportamento do emprego na indústria de transformação, portanto, foi fundamental para o comportamento do emprego formal em geral.

Contudo, é preciso destacar que o forte crescimento do emprego industrial no período entre 2003 e 2008, quando o setor chegou a contribuir com cerca de $20,0 \%$ para o crescimento do emprego formal total, e, após 2008, a reversão desse movimento, com a desaceleração do emprego na indústria, quando o setor não atingiu $8,0 \%$ de contribuição, afetou não somente o processo de geração do emprego formal, mas marcou o comportamento das categorias de menor renda média, categorias $\mathrm{C}$ e $\mathrm{D}$, de elevada participação na composição do emprego formal e em que estão concentradas as ocupações manuais ligadas à produção industrial. Sendo assim, para a análise mais detalhada do processo de evolução do emprego formal no período, é importante a observação dos dados desagregados, conforme os subsetores da indústria de transformação, abordagem do item a seguir.

\section{COMPOSIÇÃO DAS CATEGORIAS DE OCUPAÇÃO NOS SUBSETORES DA INDÚSTRIA DE TRANSFORMAÇÃO}

Igualmente aos resultados do conjunto dos setores de atividade, no setor da indústria de transformação as categorias C e D têm as maiores participações no emprego gerado. Essa 
predominância reflete não somente a estrutura econômica, mas, sobretudo, a fragilidade do sistema de relações de trabalho no país, na medida em que esse sistema não consegue barrar os efeitos que acentuam os baixos níveis salariais e a enorme dispersão da distribuição da estrutura ocupacional no país, dificultando assim o deslocamento de várias ocupações para categorias de rendas médias intermediárias e, portanto, a redução do peso das categorias de mais baixas rendas médias.

Observando o movimento do emprego na indústria de transformação, a despeito da queda do crescimento do emprego nesse setor após 2008, em praticamente todos os subsetores, com exceção apenas do subsetor "Indústria de móveis e indústrias diversas" - Tabela 7, houve crescimento da participação de todas as categorias de ocupação, exceto a D - Tabela 8.

Esse comportamento confirma o desaquecimento da geração de emprego na indústria, na medida em que a categoria $\mathrm{D}$, de menor remuneração, apresenta a maior participação e são os empregos de menor renda e menos qualificados os primeiros a serem atingidos na desaceleração da atividade econômica. Contudo, a categoria $\mathrm{D}$, mesmo registrando queda de $7,5 \%$ na participação ao longo do período, ainda foi responsável por 50,0\% dos empregos formais gerados no setor industrial. Mais de 3/4 desses empregos foram gerados nos subsetores "Preparação de couros e fabricação de artefatos de couro, artigos de viagem e calçados", "Confecção de artigos do vestuário e acessórios" e "Fabricação de produtos de madeira". Outros três subsetores nos quais a categoria D apresentou participação elevada em 2013, embora em um movimento cadente desde 2003, foram "Fabricação de produtos alimentícios e bebidas", "Fabricação de produtos têxteis" e "Fabricação de móveis e indústrias diversas", com cerca de 2/3 dos empregos gerados em cada subsetor. "Fabricação de produtos de fumo", "Fabricação de produtos de minerais não metálicos", "Edição, impressão e reprodução de gravações" e "Reciclagem" são outros subsetores da indústria em que a participação da categoria D foi de pelo menos metade do emprego gerado - Tabela 8 .

Esses dez subsetores, nos quais é muito elevada a participação da categoria de menor renda média, respondiam juntos por mais da metade do emprego industrial registrado na RAIS em 2013. Na maioria dos outros treze subsetores que, em conjunto, representaram cerca de $45,0 \%$ dos empregos gerados em 2013, foi muito menor a participação da categoria $\mathrm{D}$, com no máximo 1/4 de participação cada subsetor, com exceção de "Fabricação de papel e celulose", "Fabricação de produtos químicos" e "Fabricação de artigos de borracha e plástico", com algo em torno de $1 / 3$ de participação.

\section{TABELA 7 - VARIAC̃̃O DO EMPREGO FORMAL CONFORME SUBSETORES DA INDÚSTRIA DE TRANSFORMAÇÃO, 2003, 2008, 2013}

\begin{tabular}{|c|c|c|c|c|c|c|c|c|}
\hline \multirow[b]{2}{*}{$\begin{array}{l}\text { Indústria de Trans- } \\
\text { formação }^{1}\end{array}$} & \multirow[b]{2}{*}{$\begin{array}{c}\mathbf{N}^{0} \text { Abs. } \\
2003\end{array}$} & \multirow[b]{2}{*}{$\begin{array}{c}\text { Part. } \\
2003 \\
(\%)\end{array}$} & \multirow[b]{2}{*}{$\begin{array}{l}\mathbf{N}^{0} \text { Abs. } \\
2008\end{array}$} & \multirow[b]{2}{*}{$\begin{array}{c}\text { Part. } \\
2008 \\
(\%)\end{array}$} & \multirow[b]{2}{*}{$\begin{array}{c}\mathrm{N}^{0} \text { Abs. } \\
2013\end{array}$} & \multirow[b]{2}{*}{$\begin{array}{c}\text { Part. } \\
2013 \\
(\%)\end{array}$} & \multicolumn{2}{|c|}{ Variação (\%) } \\
\hline & & & & & & & $2003 / 08$ & $2008 / 13$ \\
\hline Alimentícios e bebidas & 1.073 .326 & 20,0 & 1.570 .594 & 20,9 & 1.666 .625 & 20,3 & 46,3 & 6,1 \\
\hline Produtos do fumo & 14.473 & 0,3 & 16.417 & 0,2 & 16.505 & 0,2 & 13,4 & 0,5 \\
\hline Produtos têxteis & 283.136 & 5,3 & 349.492 & 4,7 & 345.955 & 4,2 & 23,4 & $-1,0$ \\
\hline $\begin{array}{l}\text { Confecção vestuário e } \\
\text { acessórios }\end{array}$ & 454.824 & 8,5 & 639.318 & 8,5 & 703.212 & 8,6 & 40,6 & 10,0 \\
\hline
\end{tabular}




\begin{tabular}{lcccccccc}
\hline $\begin{array}{l}\text { Couros, artigos de via- } \\
\text { gem e calçados }\end{array}$ & 360.638 & 6,7 & 429.008 & 5,7 & 423.743 & 5,2 & 19,0 & $-1,2$ \\
\hline Produtos de madeira & 237.763 & 4,4 & 219.476 & 2,9 & 197.402 & 2,4 & $-7,7$ & $-10,1$ \\
\hline Papel e celulose & 123.581 & 2,3 & 165.824 & 2,2 & 182.410 & 2,2 & 34,2 & 10,0 \\
\hline $\begin{array}{l}\text { Edição, impressão e } \\
\text { gravações }\end{array}$ & 186.966 & 3,5 & 230.178 & 3,1 & 232.364 & 2,8 & 23,1 & 0,9 \\
\hline $\begin{array}{l}\text { Petróleo, combust. } \\
\text { nucleares e álcool }\end{array}$ & 84.238 & 1,6 & 163.831 & 2,2 & 40.529 & 0,5 & 94,5 & $-75,3$ \\
\hline Produtos químicos & 290.871 & 5,4 & 360.934 & 4,8 & 548.602 & 6,7 & 24,1 & 52,0 \\
\hline $\begin{array}{l}\text { Artigos de borracha e } \\
\text { plástico }\end{array}$ & 288.534 & 5,4 & 435.152 & 5,8 & 463.290 & 5,6 & 50,8 & 6,5 \\
\hline Minerais não metálicos & 283.895 & 5,3 & 365.106 & 4,9 & 460.166 & 5,6 & 28,6 & 26,0 \\
\hline Metalurgia básica & 199.598 & 3,7 & 266.446 & 3,6 & 254.292 & 3,1 & 33,5 & $-4,6$ \\
\hline $\begin{array}{l}\text { Produtos metal exceto } \\
\text { máquinas e equip. }\end{array}$ & 324.469 & 6,1 & 501.870 & 6,7 & 557.263 & 6,8 & 54,7 & 11,0 \\
\hline $\begin{array}{l}\text { Máquinas e equipa- } \\
\text { mentos }\end{array}$ & 286.301 & 5,3 & 489.725 & 6,5 & 604.093 & 7,4 & 71,1 & 23,4 \\
\hline $\begin{array}{l}\text { Máquinas escritório e } \\
\text { equip. de informática }\end{array}$ & 21.162 & 0,4 & 46.460 & 0,6 & 51.193 & 0,6 & 119,5 & 10,2 \\
\hline $\begin{array}{l}\text { Máquinas, aparelhos e } \\
\text { materiais elétricos }\end{array}$ & 121.049 & 2,3 & 196.931 & 2,6 & 227.268 & 2,8 & 62,7 & 15,4 \\
\hline $\begin{array}{l}\text { Aparelhos e equip. de } \\
\text { comun. }\end{array}$ & 64.693 & 1,2 & 90.321 & 1,2 & 91.181 & 1,1 & 39,6 & 1,0 \\
\hline $\begin{array}{l}\text { Equip. hospitalares, } \\
\text { instr. precisão e ópticos }\end{array}$ & 39.093 & 0,7 & 62.187 & 0,8 & 81.756 & 1,0 & 59,1 & 31,5 \\
\hline $\begin{array}{l}\text { Veículos automotores, } \\
\text { reboques e carrocerias }\end{array}$ & 283.050 & 5,3 & 453.849 & 6,1 & 511.124 & 6,2 & 60,3 & 12,6 \\
\hline $\begin{array}{l}\text { Outros equipamentos } \\
\text { de transporte }\end{array}$ & 50.609 & 0,9 & 101.788 & 1,4 & 136.672 & 1,7 & 101,1 & 34,3 \\
\hline $\begin{array}{l}\text { Móveis e indústrias } \\
\text { diversas }\end{array}$ & 271.291 & 5,1 & 315.694 & 4,2 & 388.210 & 4,7 & 16,4 & 23,0 \\
\hline Reciclagem & 14.083 & 0,3 & 28.890 & 0,4 & 33.596 & 0,4 & 105,1 & 16,3 \\
\hline \begin{tabular}{l} 
Total \\
\hline
\end{tabular} & 100 & 7.499 .491 & 100 & 8.217 .451 & 100 & 40,0 & 9,6 \\
\hline
\end{tabular}

Fonte: RAIS. Elaboração própria.

Nota 1: Setor da indústria de transformação desagregado conforme CNAE 95 Divisão.

Grande parte do emprego industrial é representada por subgrupos principais que compõem a categoria C nos subsetores "Metalurgia básica", "Fabricação de produtos de metal exceto máquinas e equipamentos", "Fabricação de máquinas e equipamentos", "Fabricação de máquinas para escritório e equipamentos de informática", "Fabricação de material eletrônico e de aparelhos e equipamento de comunicação", "Fabricação e montagem de veículos automotores, reboque e carrocerias" e "Fabricação de outros equipamentos de transporte". Em cada um desses sete subsetores, um pouco mais da metade dos empregos gerados em 2013 foi na categoria $C$. 
Outros três subsetores da indústria em que o peso da categoria C é considerável, entre 40,0\% e 50,0\%, são "Fabricação de celulose, papel e produtos de papel", "Fabricação de equipamentos de instrumentação médico-hospitalar, instrumentos de precisão e ópticos, equipamentos para automação industrial e cronômetros" e "Fabricação de máquinas, aparelhos e materiais elétricos" - ver Tabela 8. Esses dez subsetores em conjunto representavam cerca de 1/3 do emprego industrial em 2013 - Tabela 7. Como explicitado, na maioria desses subsetores, muitos desses empregos poderiam estar na categoria $\mathrm{B}$, de renda média mais elevada, caso tivéssemos um sistema de relações de trabalho mais avançado.

Um ponto importante para o qual se deve atentar é o fato de que, considerando as categorias $\mathrm{C}$ e $\mathrm{D}$, a despeito do comportamento semelhante do emprego nos dois períodos, crescendo $36,2 \%$ e $37,9 \%$, respectivamente, entre 2003 e 2008 , e desacelerando também de modo parecido entre 2008 e 2013 , quando as taxas de crescimento foram de $19,8 \%$ e $21,5 \%$, respectivamente, as medianas dos salários nas duas categorias tiveram comportamentos distintos, na medida em que a mediana da categoria $C$ cresceu mais no primeiro período $(20,3 \%$ contra $17,0 \%$ ) e a mediana da categoria $\mathrm{D}$ registrou maior crescimento no segundo momento $(13,6 \%$ contra $22,4 \%)$ - Tabela 9 . Esse movimento das medianas pode ser explicado pela forte desaceleração do crescimento do emprego industrial no segundo período, ou seja, as ocupações da categoria $\mathrm{C}$, no setor manufatureiro, têm peso elevado e são relativamente bem remuneradas, comparativamente às outras ocupações da categoria, portanto, com a redução significativa do crescimento do emprego industrial nessa categoria, caiu em maior proporção o peso dessas rendas dentro da categoria, reduzindo a mediana em C.

O coeficiente de variação dos salários médios da indústria de transformação diminuiu ao longo do período em todas as categorias, exceto na categoria A que, apesar de ligeira queda no primeiro subperíodo, registrou aumento ao final de 2013 - Tabela 10. Isso se explica pela maior dispersão dos salários quanto maior a renda média da categoria. Além disso, ao contrário dos empregos de mais baixa qualificação e menor renda, os mais qualificados são os que menos diminuem na desaceleração do crescimento, como comprovam os dados do setor industrial para a categoria $\mathrm{A}$, que mostram a menor redução do ritmo de crescimento do emprego na indústria, relativamente às outras categorias. Quanto à categoria $\mathrm{B}$, chama atenção a magnitude elevada do desvio-padrão dos salários médios dos subsetores da indústria nessa categoria que, relativamente ao salário médio da categoria, é bem mais elevado do que na categoria $\mathrm{A}$. Contudo, ao contrário da categoria $\mathrm{A}$, houve queda significativa do coeficiente de variação em $\mathrm{B}$ e a diferença entre as categorias também apresentou forte redução - Tabela 10.

TABELA 8 - COMPOSIÇÃO DO EMPREGO FORMAL CONFORME CATEGORIAS DE SUBGRUPOS PRINCIPAIS, NOS SETORES DA INDÚSTRIA DE TRANSFORMAÇÃO (\%)

\begin{tabular}{lccccccccccccccc}
\hline \multicolumn{1}{c}{$\begin{array}{c}\text { Indústria de } \\
\text { Transformação }\end{array}$} & \multicolumn{3}{c}{ Categoria A } & \multicolumn{3}{c}{ Categoria B } & \multicolumn{3}{c}{ Categoria C } & \multicolumn{4}{c}{ Categoria D } & Total \\
\cline { 2 - 13 } & $\mathbf{2 0 0 3}$ & $\mathbf{2 0 0 8}$ & $\mathbf{2 0 1 3}$ & $\mathbf{2 0 0 3}$ & $\mathbf{2 0 0 8}$ & $\mathbf{2 0 1 3}$ & $\mathbf{2 0 0 3}$ & $\mathbf{2 0 0 8}$ & $\mathbf{2 0 1 3}$ & $\mathbf{2 0 0 3}$ & $\mathbf{2 0 0 8}$ & $\mathbf{2 0 1 3}$ & \\
\hline $\begin{array}{l}\text { Alimentícios e } \\
\text { bebidas }\end{array}$ & 3,9 & 3,6 & 4,3 & 6,4 & 6,4 & 7,7 & 16,1 & 15,8 & 19,2 & 73,6 & 74,2 & 68,7 & 100 \\
\hline Produtos do fumo & 9,9 & 11,6 & 10,7 & 14,9 & 17,4 & 16,1 & 21,4 & 19,9 & 23,3 & 53,8 & 51,1 & 50,0 & 100 \\
\hline Produtos têxteis & 2,9 & 2,8 & 3,3 & 8,1 & 7,5 & 8,0 & 16,6 & 16,3 & 17,8 & 72,4 & 73,4 & 70,9 & 100 \\
\hline $\begin{array}{l}\text { Vestuário e aces- } \\
\text { sórios }\end{array}$ & 2,5 & 2,6 & 3,2 & 4,6 & 4,1 & 4,5 & 8,0 & 8,6 & 9,6 & 84,9 & 84,8 & 82,8 & 100 \\
\hline $\begin{array}{l}\text { Couros, artigos de } \\
\text { viagem e calçados }\end{array}$ & 1,3 & 1,5 & 1,8 & 3,9 & 4,4 & 6,1 & 6,4 & 7,5 & 9,0 & 88,3 & 86,6 & 83,1 & 100 \\
\hline
\end{tabular}




\begin{tabular}{|c|c|c|c|c|c|c|c|c|c|c|c|c|c|}
\hline $\begin{array}{l}\text { Produtos de ma- } \\
\text { deira }\end{array}$ & 2,8 &, 3 & 3,8 & 3,4 & 2,7 & 3,2 & 13,2 & 15,1 & 16,0 & 0,6 & 78,9 & 77,0 & 100 \\
\hline Papel e Celulose & & 6,0 & 6,4 & 1,3 & 11,0 & 1,8 & 6,1 & 41,8 & 39,6 & 7,3 & 1,2 & 42,3 & 100 \\
\hline $\begin{array}{l}\text { Edição, impressão } \\
\text { e gravações }\end{array}$ & 7,0 & 7,4 & 8,7 & 14,8 & 15,7 & 6,6 & 22,2 & 21,9 & 20,8 & 6,1 & 55,0 & 53,9 & 100 \\
\hline $\begin{array}{l}\text { Petróleo, combust. } \\
\text { nucleares e álcool }\end{array}$ & 68 & 3,6 & 6,9 & 15,8 & 12,5 & 37,7 & 18,4 & 19,0 & 13,6 & 8,9 & 64,8 & 11,8 & 100 \\
\hline Produtos químicos & 11,9 & 12,0 & 0,3 & 32,1 & 32,2 & 26,6 & & & 24,0 & & 4,2 & 39,0 & 100 \\
\hline $\begin{array}{l}\text { Artigos de borra- } \\
\text { cha e plástico }\end{array}$ & 4,1 & 4,2 & 4,9 & 35,7 & 29,8 & 0,4 & 7,1 & 28,8 & 28,2 & 3,1 & 37,1 & 36,5 & 100 \\
\hline Minerais não & 3,7 & 3,8 & 4,4 & 5,4 & 5,9 & 5,3 & 34,0 & 34,6 & 35,3 & 6,0 & 55,7 & 54,0 & 100 \\
\hline Metalurgia básica & 6,1 & 6,9 & & 150 & 15,5 & 18,8 & & & 51,9 & & & 21,5 & 100 \\
\hline $\begin{array}{l}\text { Metal exceto má- } \\
\text { quinas e equip. }\end{array}$ & 39 & 3,7 & 15 & & 86 & 9,1 & 63,6 & 61,8 & 60,2 & 24,3 & 25,9 & 26,2 & 100 \\
\hline $\begin{array}{l}\text { Máquinas e equi- } \\
\text { pamentos }\end{array}$ & 6,2 & 6,2 & 7,4 & 16,1 & 15,4 & 16,6 & 61,2 & 61,4 & 57,6 & 16,6 & 17,0 & 18,5 & 100 \\
\hline $\begin{array}{l}\text { Máquinas escrit. e } \\
\text { equip. de informát. }\end{array}$ & 14,9 & 9,7 & 10,6 & 27,2 & 17,8 & 20,7 & 47,8 & 60,2 & 55,4 & 10,1 & 12,3 & 13,4 & 100 \\
\hline $\begin{array}{l}\text { Máquinas, apare- } \\
\text { lhos, mat. elétricos }\end{array}$ & 6,5 & 7,2 & 8,1 & 15,5 & 15,0 & 16,2 & 54,8 & 52,9 & 49,2 & 23,2 & 24,9 & 26,5 & 100 \\
\hline $\begin{array}{l}\text { Aparelhos e equip. } \\
\text { de comum. }\end{array}$ & 9,5 & 9,4 & 9,7 & 19,0 & 17,0 & 18,5 & 57,7 & 53,7 & 56,5 & 13,8 & 20,0 & 15,3 & 100 \\
\hline Equip. hospitalares & 8,6 & 8,9 & 10,0 & & & & & & 44,0 & & & 25,3 & 100 \\
\hline $\begin{array}{l}\text { Veículos automo- } \\
\text { tores }\end{array}$ & 6,6 & 6,7 & 6 & 14,1 & 12,7 & 3,5 & 64,0 & 63,1 & 61,3 & 15,3 & 17,4 & 17,6 & 100 \\
\hline $\begin{array}{l}\text { Outros equip. de } \\
\text { transporte }\end{array}$ & 11,7 & 8,7 & 9,1 & 21,6 & 15,6 & 5,3 & 47,7 & 60,6 & 58,8 & 19,0 & 15,0 & 16,8 & 100 \\
\hline $\begin{array}{l}\text { Móveis e indús- } \\
\text { trias diversas }\end{array}$ & 3,3 & 3,4 & 3,9 & 6,4 & 5,3 & 6,1 & 23,8 & 23,8 & 24,2 & 66,4 & 67,5 & 65,9 & 100 \\
\hline Reciclagem & 3,6 & 4,2 & 3,9 & 12,8 & 11,0 & 10,3 & 32,0 & 28,9 & 30,0 & 51,6 & 55,9 & 55,8 & 100 \\
\hline Total & 4,7 & 4,8 & 5,7 & 11,6 & 11,3 & 12,3 & 29,4 & 30,8 & 31,8 & 54,3 & 53,2 & 50,2 & 100 \\
\hline
\end{tabular}

Fonte: RAIS. Elaboração própria.

Nota: As desproporções entre os setores de petróleo e produtos químicos tem relação com alterações na forma do registro na pesquisa RAIS.

TABELA 9 - EVOLUÇÃO DO PODER DE COMPRA DO SM E DAS MEDIANAS DOS SALÁRIOS DO EMPREGO FORMAL, CONFORME CATEGORIA DE RENDA (\%)

\begin{tabular}{ccccccc}
\hline & A & B & C & D & Total & SM \\
\hline $\mathbf{2 0 0 3 - 2 0 0 8}$ & 14,1 & 19,6 & 20,3 & 13,6 & 20,2 & 34,7 \\
\hline $\mathbf{2 0 0 8 - 2 0 1 3}$ & 6,2 & 16,6 & 17,0 & 22,4 & 21,1 & 24,0 \\
\hline $\mathbf{2 0 0 3 - 2 0 1 3}$ & 21,2 & 39,4 & 40,8 & 39,1 & 45,6 & 67,0 \\
\hline
\end{tabular}

Fonte: RAIS. Elaboração própria. 
Ao contrário do comportamento dos setores em geral, as maiores reduções dos coeficientes de variação nos subsetores da indústria de transformação foram nas categorias $\mathrm{C}$ e D. Parte importante desse comportamento está relacionado à forte desaceleração do crescimento do emprego industrial nessas categorias após 2008, sobretudo na categoria D, com a maior redução do coeficiente de variação - Tabela 10. Sendo empregos de mais baixa renda, o menor crescimento melhora a dispersão, o que igualmente explica o maior aumento da mediana dos salários também nessa categoria, no segundo subperíodo.

\section{TABELA 10 - COEFICIENTE DE VARIAÇÃO DOS SALÁRIOS MÉDIOS DA INDÚSTRIA DE TRANSFORMAÇÃO POR CATEGORIAS DE SUBGRUPOS PRINCIPAIS}

\begin{tabular}{cccc}
\hline Categorias & $\mathbf{2 0 0 3}$ & $\mathbf{2 0 0 8}$ & $\mathbf{2 0 1 3}$ \\
\hline A & 0,370 & 0,353 & 0,399 \\
\hline B & 0,502 & 0,376 & 0,436 \\
\hline C & 0,299 & 0,254 & 0,247 \\
\hline D & 0,271 & 0,228 & 0,194 \\
\hline
\end{tabular}

Fonte: RAIS. Elaboração própria.

Na categoria $\mathrm{C}$, os salários médios dos subsetores da indústria de transformação em 2013 foram relativamente elevados, acima da média da categoria, em oito subsetores, normalmente naqueles em que predominam as grandes empresas, a saber, "Fabricação de coque, refino de petróleo, elaboração de combustíveis nucleares e produção de álcool", "Fabricação de produtos de fumo", "Fabricação e montagem de veículos automotores, reboques e carrocerias" e "Fabricação de outros equipamentos de transporte". Desses subsetores, os seis últimos em conjunto tiveram geração significativa de emprego, cerca de $40,0 \%$ do emprego gerado na categoria C. Os outros $60,0 \%$ dos empregos industriais gerados na categoria $\mathrm{C}$ foram em subsetores com salários médios inferiores ao salário médio da categoria, equivalente a três salários mínimos, bem como ao salário médio da indústria em geral, pouca coisa acima do salário mínimo, sendo que cerca de 50,0\% desse total foram gerados em apenas três subsetores, "Fabricação de produtos de metal exceto máquinas e equipamentos" $(12,8 \%)$, "Fabricação de produtos alimentícios e bebidas" (12,3\%), "Fabricação de produtos minerais não metálicos" $(6,2 \%)$ - Tabelas 11 e 12 .

Na categoria D, em 2013, os salários médios, conforme os subsetores da indústria, se apresentaram inferiores ao salário médio geral do setor industrial, sendo a única exceção o subsetor "Fabricação de coque, refino de petróleo, elaboração de combustíveis nucleares e produção de álcool", porém esse subsetor registrou a menor participação na geração de emprego da categoria $(11,8 \%)$ - Tabela 11. Subsetores com participações relativamente elevadas e salários médios um pouco acima da média da categoria foram "Fabricação de produtos do fumo" (50,0\%), "Edição, impressão e reprodução de gravações" (53,9\%) e "Fabricação de celulose, papel e produtos de papel" (42,3\%) - ver Tabela 8 . Entretanto, quase 70,0\% dos empregos da categoria D foram gerados em subsetores que apresentaram salários médios inferiores ou iguais ao salário médio da categoria, cerca de dois salários mínimos, como "Fabricação de produtos alimentícios e bebidas" (27,8\%), "Confecção de artigos de vestuário e acessórios" (14,1\%), "Preparação de couro e fabricação de artefatos de couro, artigos de viagem e calçados" $(8,5 \%)$, 
"Fabricação de móveis e indústrias diversas" (6,2\%), "Fabricação de produtos minerais não metálicos" (6,0\%) e "Fabricação de produtos têxteis" (5,9\%) - Tabela 12.

Nas categorias de maiores salários médios, categorias A e B, diferentemente das categorias de salários médios inferiores, o subsetor da indústria com maior salário médio foi também aquele com maior participação do emprego da categoria em 2013, "Fabricação de coque, refino de petróleo, elaboração de combustíveis nucleares e produção de álcool". $\mathrm{Na}$ categoria $\mathrm{A}$, os subsetores com salários médios acima de dez salários mínimos geraram mais de 46,0\% dos empregos, concentrados, sobretudo, em "Fabricação de produtos químicos", "Fabricação de máquinas e equipamentos", "Fabricação e montagem de veículos automotores, reboques e carrocerias", "Fabricação de máquinas, aparelhos e materiais elétricos" e "Fabricação de coque, refino de petróleo, elaboração de combustíveis nucleares e produção de álcool" (esses setores em conjunto geraram 37,1\% dos empregos da categoria A em 2013). $\mathrm{Na}$ categoria $\mathrm{B}$, os subsetores com salários médios acima de cinco salários-mínimos, portanto acima da média salarial da categoria, geraram mais de 45,0\% dos empregos, sendo que cerca de $80,0 \%$ foram concentrados em "Fabricação de produtos químicos", "Fabricação de máquinas e equipamentos", "Fabricação e montagem de veículos automotores, reboques e carrocerias" e "Metalurgia básica" - Tabelas 11 e 12.

A estrutura salarial do setor industrial brasileiro, em contraste com a estrutura das economias desenvolvidas, confirma não apenas as enormes deficiências estruturais da nossa cadeia produtiva, mas reforça a característica frágil do nosso sistema de regulação do trabalho, que não consegue impedir a péssima distribuição da renda do trabalho, implicando a elevada concentração de ocupações de baixa renda na maioria dos subsetores da indústria, o que explica o elevado desvio-padrão em relação aos salários médios de todas as categorias de ocupação, apesar da diminuição, com exceção da categoria A, registrada ao longo do crescimento com inclusão social. Um sistema de negociações coletivas mais eficaz, com capacidade de impor pisos salariais mais elevados, promoveria o aumento das médias salariais e reduziria a elevada dispersão dos salários entre os subsetores da indústria de transformação, reduzindo a proporção das ocupações nas categorias de rendas mais baixas e elevando a proporção nas categorias de rendas mais elevadas.

\section{TABELA 11- SALÁRIOS MÉDIOS DAS CATEGORIAS DE SUBGRUPOS PRINCIPAIS POR SETORES DA INDÚSTRIA DE TRANSFORMAÇÃO, EM NÚMEROS DE SALÁRIOS- MÍNIMOS, DEZ 2013}

\begin{tabular}{|c|c|c|c|c|c|}
\hline \multirow{2}{*}{ Setores da Indústria de Transformação } & \multicolumn{4}{|c|}{ Categorias } & \multirow{2}{*}{ Total } \\
\hline & $\mathbf{A}$ & B & $\mathbf{C}$ & D & \\
\hline Alimentícios e bebidas & 9,1 & 3,7 & 2,9 & 1,9 & 2,6 \\
\hline Produtos do fumo & 15,3 & 5,7 & 4,3 & 2,8 & 5,2 \\
\hline Produtos têxteis & 8,4 & 3,6 & 2,6 & 1,9 & 2,4 \\
\hline Confecção de artigos do vestuário e acessórios & 4,2 & 2,9 & 2,1 & 1,5 & 1,7 \\
\hline Couros, artefatos de couro, artigos de viagem e calçados & 5,9 & 2,6 & 2,3 & 1,6 & 1,8 \\
\hline Produtos de madeira & 5,7 & 3,8 & 2,3 & 1,7 & 2,0 \\
\hline Papel e celulose & 12,4 & 5,5 & 3,4 & 2,4 & 3,8 \\
\hline
\end{tabular}




\begin{tabular}{lccccc}
\hline Edição, impressão e gravações & 8,0 & 5,1 & 2,7 & 2,7 & 3,5 \\
\hline Petróleo, elaboração de combustíveis nucleares e álcool & 27,9 & 18,6 & 10,0 & 4,8 & 19,2 \\
\hline Produtos químicos & 15,2 & 6,2 & 3,7 & 2,6 & 5,2 \\
\hline Artigos de borracha e plástico & 9,5 & 3,4 & 2,8 & 2,2 & 3,1 \\
\hline Minerais não metálicos & 7,7 & 4,2 & 2,2 & 2,0 & 2,4 \\
\hline Metalurgia básica & 14,0 & 5,6 & 3,6 & 3,0 & 4,7 \\
\hline Produtos de metal exceto máquinas e equipamentos & 7,8 & 4,3 & 2,7 & 2,2 & 2,9 \\
\hline Máquinas e equipamentos & 12,6 & 5,5 & 3,5 & 2,7 & 4,3 \\
\hline Máquinas para escritório e equipamentos de informática & 11,6 & 4,2 & 2,5 & 2,3 & 3,8 \\
\hline Máquinas, aparelhos e materiais elétricos & 12,1 & 4,5 & 2,9 & 2,3 & 3,8 \\
\hline Aparelhos e equipamentos de comunicações & 11,8 & 4,0 & 2,5 & 2,3 & 3,6 \\
\hline Equipamentos hospitalares & 10,3 & 4,2 & 2,7 & 2,4 & 3,7 \\
\hline Veículos automotores, reboques e carrocerias & 14,4 & 7,1 & 4,5 & 2,9 & 5,3 \\
\hline Outros equipamentos de transporte & 16,2 & 7,4 & 4,2 & 2,9 & 5,6 \\
\hline Móveis e indústrias diversas & 5,5 & 3,1 & 2,3 & 2,0 & 2,3 \\
\hline Reciclagem & 5,1 & 2,5 & 2,2 & 1,8 & 2,1 \\
\hline Total & 11,3 & 4,9 & 3,1 & 2,0 & 3,3 \\
\hline
\end{tabular}

Fonte: RAIS. Elaboração própria.

TABELA 12 - COMPOSIÇÃO DO EMPREGO FORMAL POR CATEGORIAS DE SUBGRUPOS PRINCIPAIS, CONFORME SETORES DA INDÚSTRIA DE TRANSFORMAÇÃO (\%)

\begin{tabular}{|c|c|c|c|c|c|c|c|c|c|c|c|c|}
\hline \multirow{2}{*}{$\begin{array}{c}\text { Indústria Transfor- } \\
\text { mação }\end{array}$} & \multicolumn{3}{|c|}{ Categoria A } & \multicolumn{3}{|c|}{ Categoria B } & \multicolumn{3}{|c|}{ Categoria C } & \multicolumn{3}{|c|}{ Categoria D } \\
\hline & 2003 & 2008 & 2013 & 2003 & 2008 & 2013 & 2003 & 2008 & 2013 & 2003 & 2008 & 2013 \\
\hline $\begin{array}{l}\text { Alimentícios e be- } \\
\text { bidas }\end{array}$ & 16,4 & 16,0 & 15,3 & 11,0 & 11,9 & 12,8 & 11,0 & 10,7 & 12,3 & 27,2 & 29,2 & 27,8 \\
\hline Produtos do fumo & 0,6 & 0,5 & 0,4 & 0,3 & 0,3 & 0,3 & 0,2 & 0,1 & 0,1 & 0,3 & 0,2 & 0,2 \\
\hline Produtos têxteis & 3,2 & 2,7 & 2,4 & 3,7 & 3,1 & 2,7 & 3,0 & 2,5 & 2,4 & 7,0 & 6,4 & 5,9 \\
\hline $\begin{array}{l}\text { Confecção de artigos } \\
\text { do vestuário e aces- } \\
\text { sórios }\end{array}$ & 4,5 & 4,7 & 4,8 & 3,3 & 3,1 & 3,1 & 2,3 & 2,4 & 2,6 & 13,3 & 13,6 & 14,1 \\
\hline $\begin{array}{l}\text { Couros, artefatos } \\
\text { de couro, artigos de } \\
\text { viagem e calçados }\end{array}$ & 1,9 & 1,7 & 1,6 & 2,3 & 2,3 & 2,6 & 1,5 & 1,4 & 1,5 & 11,0 & 9,3 & 8,5 \\
\hline Produtos de madeira & 2,6 & 2,0 & 1,6 & 1,3 & 0,7 & 0,6 & 2,0 & 1,4 & 1,2 & 6,6 & 4,3 & 3,7 \\
\hline Papel e celulose & 2,6 & 2,8 & 2,5 & 2,2 & 2,2 & 2,1 & 3,6 & 3,0 & 2,8 & 1,6 & 1,7 & 1,9 \\
\hline
\end{tabular}




\begin{tabular}{|c|c|c|c|c|c|c|c|c|c|c|c|c|}
\hline $\begin{array}{l}\text { Edição, impressão e } \\
\text { gravações }\end{array}$ & 5,1 & 4,8 & 4,3 & 4,4 & 4,3 & 3,8 & 2,6 & 2,2 & 1,9 & 3,6 & 3,2 & 3,0 \\
\hline $\begin{array}{l}\text { Petróleo, elaboração } \\
\text { de combustíveis } \\
\text { nucleares e álcool }\end{array}$ & 2,3 & 1,6 & 3,2 & 2,1 & 2,4 & 1,5 & 1,0 & 1,4 & 0,2 & 1,7 & 2,7 & 0,1 \\
\hline Produtos químicos & 13,7 & 12,0 & 12,2 & 15,0 & 13,8 & 14,5 & 4,3 & 3,4 & 5,0 & 3,3 & 3,1 & 5,2 \\
\hline $\begin{array}{l}\text { Artigos de borracha e } \\
\text { plástico }\end{array}$ & 4,7 & 5,1 & 4,9 & 16,5 & 15,4 & 13,9 & 5,0 & 5,4 & 5,0 & 3,3 & 4,1 & 4,1 \\
\hline $\begin{array}{l}\text { Produtos de minerais } \\
\text { nãometálicos }\end{array}$ & 4,2 & 3,9 & 4,3 & 2,9 & 2,6 & 2,9 & 6,1 & 5,5 & 6,2 & 5,5 & 5,1 & 6,0 \\
\hline Metalurgia básica & 4,8 & 5,1 & 4,3 & 4,9 & 4,9 & 4,7 & 7,2 & 6,4 & 5,0 & 1,5 & 1,5 & 1,3 \\
\hline $\begin{array}{l}\text { Produtos de metal } \\
\text { exceto máquinas e } \\
\text { equipamentos }\end{array}$ & 4,9 & 5,2 & 5,4 & 4,3 & 5,1 & 5,0 & 13,1 & 13,4 & 12,8 & 2,7 & 3,3 & 3,5 \\
\hline $\begin{array}{l}\text { Máquinas e equipa- } \\
\text { mentos }\end{array}$ & 7,0 & 8,4 & 9,5 & 7,4 & 9,0 & 9,9 & 11,1 & 13,0 & 13,3 & 1,6 & 2,1 & 2,7 \\
\hline $\begin{array}{l}\text { Máquinas para escri- } \\
\text { tório e equipamentos } \\
\text { de informática }\end{array}$ & 1,2 & 1,3 & 1,2 & 0,9 & 1,0 & 1,0 & 0,6 & 1,2 & 1,1 & 0,1 & 0,1 & 0,2 \\
\hline $\begin{array}{l}\text { Máquinas, aparelhos } \\
\text { e materiais elétricos }\end{array}$ & 3,1 & 4,0 & 3,9 & 3,0 & 3,5 & 3,6 & 4,2 & 4,5 & 4,3 & 1,0 & 1,2 & 1,5 \\
\hline $\begin{array}{l}\text { Aparelhos e equipa- } \\
\text { mentos de comuni- } \\
\text { cações }\end{array}$ & 2,4 & 2,4 & 1,9 & 2,0 & 1,8 & 1,7 & 2,4 & 2,1 & 2,0 & 0,3 & 0,5 & 0,3 \\
\hline $\begin{array}{l}\text { Equipamentos hospi- } \\
\text { talares }\end{array}$ & 1,3 & 1,5 & 1,8 & 1,2 & 1,5 & 1,7 & 1,2 & 1,3 & 1,4 & 0,3 & 0,4 & 0,5 \\
\hline $\begin{array}{l}\text { Veículos automo- } \\
\text { tores, reboques e } \\
\text { carrocerias }\end{array}$ & 7,3 & 8,5 & 8,3 & 6,4 & 6,9 & 6,8 & 11,5 & 12,4 & 12,0 & 1,5 & 2,0 & 2,2 \\
\hline $\begin{array}{l}\text { Outros equipamentos } \\
\text { de transporte }\end{array}$ & 2,3 & 2,5 & 2,7 & 1,8 & 1,9 & 2,1 & 1,5 & 2,7 & 3,1 & 0,3 & 0,4 & 0,6 \\
\hline $\begin{array}{l}\text { Móveis e indústrias } \\
\text { diversas }\end{array}$ & 3,6 & 3,0 & 3,3 & 2,8 & 2,0 & 2,3 & 4,1 & 3,3 & 3,6 & 6,2 & 5,3 & 6,2 \\
\hline Reciclagem & 0,2 & 0,3 & 0,3 & 0,3 & 0,4 & 0,3 & 0,3 & 0,4 & 0,4 & 0,2 & 0,4 & 0,5 \\
\hline Total & 100 & 100 & 100 & 100 & 100 & 100 & 100 & 100 & 100 & 100 & 100 & 100 \\
\hline
\end{tabular}

Fonte: RAIS. Elaboração própria.

Nota: As desproporções entre os setores de petróleo e produtos químicos tem relação com alterações na forma do registro na pesquisa RAIS.

\section{CONCLUSÃO}

A análise do presente artigo destacou características da distribuição salarial do emprego formal registrado na RAIS, de elevada desigualdade, e que ainda se mantêm, embora tenha ocorrido uma expressiva redução das diferenças dos níveis de salários, ao longo do crescimento com inclusão social, entre 2003 e 2013. Os principais mecanismos promotores dessa redução da desigualdade salarial foram os ganhos de poder de compra do salário-mínimo e os reajustes dos salários das categorias profissionais acima da inflação, em um cenário de crescimento 
econômico com forte aumento do emprego formal, para além do crescimento do PIB, e inflação relativamente baixa.

A análise da evolução da distribuição dos salários do emprego formal nessa fase, com base na classificação formada por quatro categorias de renda, em função da remuneração média, utilizando-se os subgrupos principais da CBO, permitiu identificar alterações na distribuição dos salários, juntamente a modificações na composição do emprego por categoria e nas diferenças dos níveis salariais das categorias, resultando em diminuições nos graus de assimetria e dispersão relativa dos salários do total dos empregos formais registrados na RAIS. Essas alterações se explicitaram com mais força após a crise internacional de 2008, quando se verificou a desaceleração do crescimento do PIB. O coeficiente de variação dos salários do conjunto dos empregos formais diminuiu nos dois subperíodos, porém, mais fortemente entre 2008 e 2013 do que entre 2003 e 2008. Já a proporção dos empregos com renda menor que a média teve um ligeiro aumento no primeiro subperíodo e redução no segundo momento.

A despeito da desaceleração do crescimento do PIB e do emprego formal após 2008, aprofundaram-se as reduções da assimetria e dispersão relativa da distribuição dos salários dos empregos da RAIS. O crescimento desses empregos continuou expressivo com a continuidade da formalização da atividade econômica. O poder de compra das menores remunerações continuou aumentando, embora com menos intensidade, devido à menor elevação do valor do salário-mínimo, com a desaceleração do PIB. O aumento do poder de compra dos salários médio e mediano, entretanto, não arrefeceu com a desaceleração da economia.

Apesar da expressiva redução na dispersão e assimetria da distribuição salarial no final do período analisado, ainda é muito grande a desigualdade dentro de e entre categorias ocupacionais. Ademais, a elevada participação da categoria de ocupações de baixo salário médio permaneceu como característica marcante da nossa estrutura ocupacional, ou seja, a despeito do intenso aumento do emprego formal e da significativa redução da dispersão e assimetria da distribuição dos salários, após o aumento do valor do salário mínimo e dos ganhos de poder de compra dos salários das categorias profissionais, não ocorreram deslocamentos de subgrupos principais para categorias de maior salário médio e não se modificou a distribuição do emprego formal por categoria de subgrupo principal, definidas pelo salário médio, contribuindo para que a categoria de menor salário médio continuasse a responder por metade dos empregos da RAIS, ao final do período de crescimento com inclusão social.

Como largamente apontado na literatura sobre o tema, não houve avanço produtivo considerável durante essa fase, a ponto de ampliar substancialmente a participação das categorias de maior salário médio. No subperíodo de maior crescimento do PIB (2003 a 2008), a produção manufatureira ampliou-se e gerou volume significativo de emprego formal. Não obstante foi muito intensa a importação de produtos manufaturados de alto conteúdo tecnológico, e o país não chegou a reduzir significativamente o atraso tecnológico acumulado durante os anos 1980 e 1990, o que tornou o atendimento da demanda de bens manufaturados altamente dependente da importação de insumos sofisticados não produzidos no país. Essa debilidade tecnológicoprodutiva do nosso sistema de produção, sem lugar à dúvida, vem interferindo não somente na nossa dinâmica de crescimento, mas também prejudicando imensamente a qualidade e a renda dos empregos gerados, problemas que tendem a se agravar diante do avanço do novo ciclo de inovações tecnológicas, relativo ao que se denomina indústria 4.0.

Dessa forma, a debilidade do desenvolvimento da produção no crescimento com inclusão social responde pela pequena ampliação na participação das categorias de subgrupos principais de maior salário médio, contudo a continuidade da alta participação das duas categorias 
de salários médios mais baixos tem mais a ver com a debilidade do sistema de relações de trabalho no Brasil. Nos períodos de maior desenvolvimento econômico, as condições políticas não favoreceram o estabelecimento de categorias profissionais de âmbito nacional, capazes de impor pisos salariais consistentes com a importância das principais atividades que geram aqueles tipos de emprego, não ajudando a impedir a elevada dispersão salarial, associada a diferenças de setor de atividade, tamanho de empresa, tipo de empregador e região geográfica.

A debilidade do sistema de relações de trabalho é fundamental para explicar a enorme dispersão de salários, principalmente para o trabalho manual na produção de bens. Sem organizações de âmbito nacional, capazes de impor pisos salariais adequados, prevaleceu ampla dispersão salarial por atividade, tamanho de empresa, tipo de empregador e região geográfica, fazendo com que os salários médios dos subgrupos principais correspondentes fossem relativamente baixos, confundindo-se com os subgrupos principais de outras ocupações, com maiores dificuldades de se organizar nacionalmente, e, portanto, de impedir maior dispersão salarial por atividade, tamanho de empresa, tipo de empregador e região geográfica.

Nessas condições, nossa estrutura ocupacional se caracteriza por elevada proporção do emprego formal nas duas categorias de salários médios mais baixos, razão principal, ao lado da baixa participação do emprego formal das duas categorias de altos salários médios, da elevada assimetria da distribuição dos salários do emprego formal. A elevação do valor do salário-mínimo e os ganhos de poder de compra dos salários das categorias profissionais diminuíram a dispersão dentro e entre as categorias de subgrupos principais, segundo o salário médio. Todavia, as reduções da assimetria e dispersão da distribuição dos salários do emprego formal foram relativamente lentas ao não existirem categorias profissionais de trabalho manual nacionalmente estruturadas, com pisos salariais condizentes com as principais atividades que geram os empregos desse tipo. Sem essas mudanças mais fortes na dispersão salarial, decorrentes da institucionalidade das relações de trabalho, é possível especular que com um desenvolvimento mais intenso da produção de bens, elevando a participação das duas categorias de subgrupos principais de maiores salários médios, seria possível reduzir o grau de assimetria da distribuição dos salários dos empregos formais, porém a dispersão relativa dos salários poderia diminuir ainda mais lentamente, com base nos efeitos do aumento do valor do salário mínimo e dos ganhos de poder de compra dos salários das categorias profissionais, sem uma institucionalidade adequada das relações de trabalho, que colocasse maior proporção de empregos formais no centro da distribuição dos salários.

O fato é que, a despeito do crescimento econômico e da forte elevação do emprego formal com melhora considerável da distribuição salarial no Brasil, entre 2003 e 2013, promovendo um ciclo de significativa inclusão de parte expressiva da base da pirâmide social, não foi possível provocar uma transformação na configuração da estrutura de ocupações formais, a qual se mantém com uma distribuição ainda muito díspar e assimétrica.

Desse modo, podemos concluir que mesmo com a trajetória de recuperação do poder de compra do salário mínimo ao longo de todo o período, bem como com as conquistas de reajustes acima da inflação por parte das categorias profissionais, a despeito de terem viabilizado a maior inclusão dos trabalhadores, esses instrumentos não foram suficientes, nesse processo e nesse intervalo de tempo, para alterar mais expressivamente a curva de distribuição das ocupações conforme a renda. 


\section{REFERÊNCIAS}

BALTAR, C. T. Economic growth and inflation in open developing economy: the case of Brazil. 2013. Tese (Doutorado) - University of Cambridge, 2013.

BALTAR, P. E. A.; LEONE, E. T. Perspectivas para o mercado de trabalho após o crescimento com inclusão social. Estudos Avançados, São Paulo, v. 29, n. 85, set./dez. 2015.

BALTAR, P. E. A. et al. Trabalho no governo Lula; uma reflexão sobre a recente experiência brasileira. Global Labour University Working Papers. Paper nº 9, maio de 2010.

BARBOSA, N.; PEREIRA de SOUZA. J. A. A inflexão do governo Lula: política econômica, crescimento e distribuição de renda. In: SADER, E.; GARCIA, M. A. (Orgs.). Brasil entre o passado e o futuro. São Paulo: Boitempo/Fundação Perseu Abramo, 2010.

BIANCARELLI, A. M. A era Lula e sua questão econômica principal: crescimento, mercado interno e distribuição de renda. Revista do Instituto de Estudos Brasileiros, São Paulo, v. 58, p. 263-288, jun. 2014.

CANO, W. A desindustrialização no Brasil. Texto para discussão, n. 200. Campinas: Ed. Da Unicamp, 2012.

CNI. Indústria brasileira perde competitividade há uma década. Nota Econômica. CNI. ano 1, n. 1, jan. 2015.

CNM/CUT/DIEESE. A indústria siderúrgica e da metalurgia Básica no Brasil: diagnóstico e propostas elaboradas pelos metalúrgicos da CUT. São Paulo: CNM/CUT/DIEESE, 2012.

COMIN, A. A desindustrialização truncada: perspectivas do desenvolvimento econômico brasileiro. 2009. Tese (Doutorado) - Instituto de Economia, Universidade Estadual de Campinas, Campinas, 2009.

COUTINHO, L. A. Especialização regressiva: um balanço do desempenho industrial pósestabilização. In: IX Fórum Nacional - Brasil: desafios de um país em transformação. Rio de Janeiro: José Olympio, 1997.

COUTINHO, L.; BELLUZZO, L. G. Desenvolvimento e estabilização sob finanças globalizadas. Economia e Sociedade, Campinas, n. 7, dez. 1996.

COSTA, M. da S. O sistema de relações de trabalho no Brasil: alguns traços históricos e sua precarização atual. Revista Brasileira de Ciências Sociais, v. 20, n. 59, out. 2005.

CRUZ, B. O.; SANTOS, I. R. S. Dinâmica do emprego industrial no Brasil entre 1990 e 2009: uma visão regional da desindustrialização. Texto para discussão, n. 1673. Rio de Janeiro: IPEA, 2011.

DEDECCA, C. S. Notas sobre a evolução do mercado de trabalho no Brasil. Revista de Economia Política, v. 25, n. 1, jan.- mar., 2005.

DEDECCA, C. S. Racionalização econômica e trabalho no capitalismo avançado. Campinas: Ed. da Unicamp, 1999.

DEDECCA, C. S.; MENEZES, A. Contratualidade das relações de trabalho: as experiências sueca, francesa e italiana. Revista de Economia Política, São Paulo, 1995.

DIEESE. A situação do trabalho no Brasil na primeira década dos anos 2000. São Paulo: Departamento Intersindical de Estatística e Estudos Socioeconômicos, 2012. 
HIRATUKA, C.; SARTI, F. Transformações na estrutura produtiva global, desindustrialização e desenvolvimento industrial no Brasil: uma contribuição para o debate. Texto para discussão, n. 255. Campinas: Ed. da Unicamp, 2015.

KREIN, J. D. et. al. Relações de trabalho. Texto para discussão, n. 4. Campinas: CESIT/IE/ Unicamp, 2017.

KUPFER, D. Desenvolvimento é crescimento com mudança estrutural. Revista do Instituto Humanistas Unisinos, n. 392, 14 maio 2012. Disponível em: http://www.ihuonline.unisinos. br/index.php?option $=$ com_content\&view $=$ article $\& i d=4426 \&$ secao $=392$. Acesso em: 31 jun. 2015.

MEDEIROS, C. A. de. Inserção externa, crescimento e padrão de consumo na economia brasileira. Brasília: IPEA, 2015.

SABOIA, J. Elasticidades dos rendimentos do trabalho em relação ao salário-mínimo. Economia e Sociedade, Campinas, v. 19, n. 2, ago. 2010.

SOUEN, J. A. A política de salário-mínimo no governo Lula. 2013. Dissertação (Mestrado) - Instituto de Economia, Universidade Estadual de Campinas, Campinas, 2013.

SOUEN, J. A. A evolução do emprego formal no crescimento com inclusão social, 2003-2013. Tese (Doutorado) - Instituto de Economia, Universidade Estadual de Campinas, Campinas, 2018.

SOUZA CAMPOS, G. C. O emprego formal no Brasil nos anos 2000: um estudo da Relação Anual de Informações Sociais (2003-2013). Dissertação (Mestrado) - Instituto de Economia, Universidade Estadual de Campinas, Campinas, 2016.

\section{ANEXO 1 - DISTRIBUIÇÃO DOS SUBGRUPOS PRINCIPAIS POR CATEGORIAS DE} RENDA MÉDIA, 2013

\begin{tabular}{clcc}
\hline Categorias & \multicolumn{1}{c}{ Subgrupos principais } & No Abs. $^{\mathbf{c}}$ & Média \\
\hline & Profissionais das ciências jurídicas & 131.442 & $10.639,28$ \\
\cline { 2 - 4 } & $\begin{array}{l}\text { Dirigentes de empresas e organizações (exceto de interesse } \\
\text { público) }\end{array}$ & 129.066 & $10.474,95$ \\
\cline { 2 - 4 } & Pesquisadores e profissionais policientificos & 31.841 & $9.540,19$ \\
\cline { 2 - 4 } A & Profissionais das ciências exatas, físicas e da engenharia & 574.916 & $7.510,61$ \\
\cline { 2 - 4 } & Profissionais das ciências sociais e humanas & 978.259 & $5.166,11$ \\
\cline { 2 - 4 } & Gerentes & 1.346 .362 & $4.840,14$ \\
\cline { 2 - 4 } & Profissionais das ciências biológicas, da saúde e afins & 893.559 & $4.701,65$ \\
\cline { 2 - 4 } & Membros superiores e dirigentes do poder publico & 778.888 & $4.343,76$ \\
\cline { 2 - 4 } & Diretores e gerentes em empresa de saúde, educação e cultura & 92.849 & $4.340,32$ \\
\hline Subtotal & \multicolumn{2}{c}{4.957 .182} & $5.432,53$ \\
\hline
\end{tabular}




\begin{tabular}{|c|c|c|c|}
\hline \multirow{10}{*}{ B } & $\{\tilde{n}$ class $\}$ & 787.834 & $3.838,40$ \\
\hline & Técnicos nível médio nas ciências administrativas & 1.156 .566 & $3.601,94$ \\
\hline & Comunicadores, artistas e religiosos & 175.081 & $3.417,14$ \\
\hline & Técnicos polivalentes & 59.026 & $3.303,87$ \\
\hline & $\begin{array}{l}\text { Técnicos nível médio das ciências físicas, químicas, engenha- } \\
\text { ria e afins }\end{array}$ & 888.205 & $3.106,14$ \\
\hline & Profissionais do ensino & 2.328 .914 & $3.088,03$ \\
\hline & Outros técnicos nível médio & 355.798 & $3.011,92$ \\
\hline & $\begin{array}{l}\text { Trabalhadores em indústrias de processos contínuos e outras } \\
\text { indústrias }\end{array}$ & 288.503 & $2.958,48$ \\
\hline & Técnicos nível médio em serviços de transportes & 166.229 & $2.947,63$ \\
\hline & Polimantenedores & 213.461 & $2.608,04$ \\
\hline Subtotal & & 6.419 .617 & $3.256,53$ \\
\hline \multirow{12}{*}{$\mathbf{C}$} & $\begin{array}{l}\text { Trabalhadores em serviços de reparação e manutenção mecâ- } \\
\text { nica }\end{array}$ & 654.592 & $2.182,59$ \\
\hline & Trabalhadores da transformação de metais e de compósitos & 1.482 .179 & $2.161,19$ \\
\hline & $\begin{array}{l}\text { Operadores de produção, captação, tratamento e distr. (energia, } \\
\text { água e utilidad }\end{array}$ & 265.279 & $2.150,03$ \\
\hline & Escriturários & 7.141 .605 & $2.129,98$ \\
\hline & Montadores de aparelhos e instrumentos de precisão e musicais & 11.954 & $2.066,73$ \\
\hline & Professores leigos e de nível médio & 1.339 .838 & $2.042,80$ \\
\hline & Trabalhadores de instalações e máquinas para papel e celulose & 47.014 & $2.015,68$ \\
\hline & Técnicos nível médio da cultura, comunicações e desportos & 177.213 & $1.958,92$ \\
\hline & $\begin{array}{l}\text { Técnicos nível médio ciências biológicas, bioquímicas, saúde } \\
\text { e afins }\end{array}$ & 1.122 .050 & $1.830,41$ \\
\hline & Trabalhadores da fabricação e instalação eletroeletrônica & 313.493 & $1.814,10$ \\
\hline & Trabalhadores da mecanização agropecuária e florestal & 218.486 & $1.700,84$ \\
\hline & Trabalhadores siderúrgicas e de materiais const. & 215.774 & $1.666,90$ \\
\hline Subtotal & & 12.989 .477 & $2.076,39$ \\
\hline \multirow{13}{*}{$\mathbf{D}$} & Trabalhadores de funções transversais & 3.968 .123 & $1.500,46$ \\
\hline & Trabalhadores da indústria extrativa e da construção civil & 2.633 .712 & $1.437,66$ \\
\hline & Vendedores e prestadores de serviços do comercio & 3.656 .719 & $1.399,92$ \\
\hline & Trabalhadores das indústrias de madeira e do mobiliário & 312.515 & $1.380,31$ \\
\hline & Joalheiros, vidreiros, ceramistas e afins & 74.789 & $1.376,20$ \\
\hline & Trabalhadores da fabricação de alimentos, bebidas e fumo & 829.717 & $1.281,96$ \\
\hline & Outros trabalhadores da conservação, manutenção e reparação & 320.592 & $1.203,49$ \\
\hline & $\begin{array}{l}\text { Trabalhadores nas indústrias têxtil, do curtimento, do vestuário } \\
\text { e das artes gráficas }\end{array}$ & 1.242 .433 & $1.199,65$ \\
\hline & Trabalhadores dos serviços & 7.814 .454 & $1.189,30$ \\
\hline & Trabalhadores de atendimento ao público & 2.427 .034 & $1.142,08$ \\
\hline & Pescadores e extrativistas florestais & 103.879 & $1.077,10$ \\
\hline & Trabalhadores na exploração agropecuária & 1.179 .591 & $1.062,40$ \\
\hline & Produtores na exploração agropecuária & 18.599 & $1.017,69$ \\
\hline Subtotal & & 24.582 .157 & $1.292,94$ \\
\hline Total & & 48.948 .433 & $2.177,60$ \\
\hline
\end{tabular}

Fonte: RAIS. Elaboração própria. 
Notas: 1. Classificação por categorias de renda média em ordem decrescente, conforme os estoques de dezembro de 2013. Categoria A: alta renda média; Categoria B: média alta renda média; Categoria C: média renda média; Categoria D: baixa renda média.

2. Considerado as ocupações conforme CBO 2002 subgrupos principais. Utilizados estoques de dezembro de 2013.

3. Para efeito de comparação com os dados de 2003 e 2008, os dados de 2013 foram compatibilizados. Para o ano de 2013 o subgrupo principal "Trabalhadores dos serviços" (51) agrega o subgrupo "Profissionais da gastronomia" (27) e o subgrupo principal "Profissionais da indústria têxtil, curtimento e vestuário" (76) agrega o subgrupo "Trabalhadores do artesanato" (79). 